\title{
Engagement and Attainment: The Longer-Run Effects of Ethnic Studies
}

\author{
Sade Bonilla
}

Thomas S. Dee

Emily K. Penner

May 2021

Sade Bonilla

College of Education

Center for Student Success Research

University of Massachusetts, Amherst 813 N. Pleasant St.

Amherst, MA 01003

sadebonilla@umass.edu

Emily K. Penner

School of Education

University of California, Irvine

3200 Education

Irvine, CA 92617

emily.penner@uci.edu
Thomas S. Dee

Graduate School of Education

Stanford University

520 Galvez Mall

Stanford, CA 94305

and NBER

tdee@stanford.edu 


\begin{abstract}
Increased interest in anti-racist education has motivated the rapidly growing but politically contentious adoption of ethnic-studies (ES) courses in U.S. public schools. A long-standing rationale for ES courses is that their emphasis on culturally relevant and critically engaged content (e.g., social justice, anti-racism, stereotypes, contemporary social movements) has potent effects on student engagement and outcomes. However, the quantitative evidence supporting this claim is limited. In this preregistered, regression-discontinuity study, we examine the longer-run impact of a grade-9 ES course offered in the San Francisco Unified School District (SFUSD). Our key confirmatory finding is that assignment to this course significantly increased the probability of high-school graduation among students near the grade-GPA threshold (i.e., 2.0 GPA in grade 8) used for assigning students to the course. Our exploratory analyses also indicate that this assignment increased measures of engagement throughout high school (e.g., attendance) as well as the probability of postsecondary matriculation.
\end{abstract}

\title{
SIGNIFICANCE
}

Anti-racist curricula and teaching methods represent a way for schools to better promote a just society and improve educational outcomes for low-income and students of color. A prominent example of culturally relevant and critically engaged content is the growing adoption of ethnic-studies (ES) courses in K-12 schools. Proponents tout the benefits of ES for increasing student engagement and academic outcomes, yet there is little causal evidence supporting these claims. In this study, we use a preregistered regression discontinuity research design to identify the longer-term impacts on educational attainment and engagement of being assigned to an ES course in grade-9. We find that assignment to ES substantially increased high school graduation, attendance, and the probability of enrolling in college. 


\section{Acknowledgements}

We are grateful for the financial support provided by the Mindset Scholars Network, Spencer Foundation and W.T. Grant Foundation. Chirag Lala and Emely Medina provided excellent research assistance. Any errors are attributable to the authors. We acknowledge institutional support from the University of Massachusetts Amherst, Stanford University, and University of California, Irvine. 


\section{Introduction}

Recent, high-profile incidents of police violence in the U.S. have brought increased public attention to contemporary manifestations of systemic racism in U.S. society and catalyzed a corresponding interest in how key institutions such as schools can better promote a just society. In education, this focus has included renewed attention to the design and impact of curricula and teaching methods with distinct anti-racist features (American Educational Research Association and National Academy of Education, 2020). A prominent example is the growing interest in ethnic-studies (ES) courses. In general, ES courses focus on the histories of historically marginalized communities, the promotion of students' critical awareness of social issues, and the encouragement of civic engagement and community-responsive social justice. Today, a growing number of school districts and states are offering ES courses to K-12 students and, in some cases, passing ES-course requirements for all students (e.g., Zavala et al., 2019; Flannery, 2020).

The increased interest in ES courses has not been without controversy. Critics argue that ES courses are a biased and politically charged indoctrination that constitutes a form of "reverse racism" (e.g., Nicol, 2013; Gecker, 2021). Proponents counter that the need for ES courses needs to be understood in the historical context of the United States' development and growth, which has consistently included overt oppression of and marginalization of racialized and ethnic minorities (Sleeter and Zavala, 2020). Over 50 years ago, the field of Ethnic Studies emerged in response to this historical awareness and the recognition that the perspectives of communities of color had been excluded from the nation's curricula. Specifically, during and after the social movements of the 1960s, communities of color and student coalitions like the Third World Liberation Front advocated for Ethnic Studies as a way to increase educational access, inclusion, and autonomy for faculty and students of color and to field new curricula that reflected the experiences and struggles of historically marginalized groups in the U.S. (Sleeter et al. 2019; Sleeter and Zavala, 2020).

The current debate over ES courses also turns on opposing claims about their educational effects. Critics argue that ES courses lack academic rigor and replace "reasoning through logic and consideration of evidence" with "a vague deconstruction of power relationships" (Evers, 2019; Nicol, 2013). In contrast, ES proponents often make strong claims about how ES courses can substantially improve academic engagement, critical thinking, and longer-run student success (Sleeter, 2011; Sleeter and Zavala, 2020). Several qualitative studies have presented evidence that ES courses have positive effects on student engagement (i.e., sense of identity, school belongingness), student achievement, and high school graduation (see Sleeter and Zavala, 2020 for a summary). However, there are only two quantitative studies examining the relationship between taking an ES course and student outcomes. Cabrera, Milem, Jaquette, \& Marx (2014) found that voluntary participation in Tucson's Mexican American Studies (MAS) program was associated with increases in standardized test pass rates and high school graduation.

This promising descriptive evidence is further corroborated by Dee and Penner's (2017) causal evaluation of the effects of the San Francisco Unified School District's (SFUSD) pilot ES course. Using a regression-discontinuity design, that study found that participation in the grade-9 ES course substantially increased attendance, credits earned, and grades as measured at the end of the school year. That study effectively relied on comparisons across students whose grade-8 GPA placed them below or above the 2.0 threshold that was used for course assignment during the developmentally sensitive transition to high school. However, the fadeout of short-term gains like these is common in educational interventions (Bailey et al. 2017) so these effects may not be sustained when students return to conventional academic programs. Alternatively, if students subsequently encounter supportive learning environments that continue to foster personal and academic growth, participation 
in the ES course may lead to a reinforcing cycle of improved engagement and academic success that sustains or even enhances longer-run educational outcomes (Yeager and Walton, 2011).

In the current study, we present the results from a pre-registered regression discontinuity design that examines the longer-run effects of the ES course among the students in the original Dee and Penner (2017) sample. ${ }^{1}$ We find evidence that ES enrollment substantially increased the probability of graduating from high school, an outcome with important life-long benefits with respect to a variety of outcomes including health and economic success. We also find complementary evidence that participation in the grade-9 ES course promoted student engagement and persistence throughout high school (i.e., enrollment, attendance and credits earned) and that these gains may also extend to postsecondary enrollment. Finally, we note some important caveats of our research sample and design that have implications for our study's generalizability and efforts to replicate and scale these results. First, our study relies on data from five cohorts that opted to offer ES in a pilot program where teacher's received intensive training in developing ES courses. Second, participating schools served lower-performing students who were more likely to have disabilities and identify as Latinx than the general SFUSD population. Third, although this smaller-scale implementation of ES has strong causal warrant due to the regression discontinuity design, the impacts are estimated for those academically low-performing students targeted for ES enrollment. As such, our impacts are defined for those students near the 2.0 GPA threshold who complied with their ES assignment.

\section{Background}

In 2010, SFUSD's Board of Education unanimously passed a resolution, requesting that the Superintendent fund and implement a pilot ethnic-studies (ES) course in SFUSD high schools. The resolution also asked that this course meet the University of California's certification as a collegepreparatory elective. A "collective" of ten social-studies teachers developed and tested course materials for a year-long grade-9 course with support from faculty at San Francisco State University and the District's Office of Learning Support and Equity (SFUSD Ethnic Studies Curriculum Collective, 2012). Several teachers from this collective became the first to formally implement the course in several high schools between the 2010-11 and 2013-14 school years.

The units in this course focused on themes of social justice, anti-racism, stereotypes, and social movements led by people of color from U.S. history spanning the late $18^{\text {th }}$ century until the 1970 s. The curriculum incorporated elements of histories and political struggles of multiple racial and ethnic groups, many of which are not traditionally represented in US social-studies content. For example, students in this course examined the genocide of Native Americans in California, community resistance in historical Chinese and Latino neighborhoods in California, and labor organizing during the Great Depression and World War II among African Americans and Filipino Americans. The course also encouraged students to explore how social constructions of race, ethnicity, and culture shaped their individual identity, their family and community histories and required students to design and implement participatory-action projects based on their study of race and ethnic relations in their local communities. The learning objectives of the course included student knowledge of and ability to combat racism and other forms of oppression, increased student commitment to social justice, and improvement of student pride in their own identities and communities. In addition to the civic and psychological goals of the ES program, the program's stated intent was to close achievement gaps and reduce dropout rates (Office of Learning Support and Equity/Humanities, Academics and Professional Development, 2009; SFUSD Ethnic Studies Curriculum Collective, 2012).

\footnotetext{
${ }^{1}$ Our study pre-registration is available here: osf.io/89mrt. Prior to having access to the data, we identified high-school graduation as our confirmatory outcome.
} 
The conceptual foundations for ES courses are closely related to an influential literature in education research on "culturally relevant pedagogy" (CRP). The definition of CRP stresses three broad features of culturally relevant instruction (Ladson-Billings, 1995). These include both prioritizing students' academic success and simultaneously providing "a way for students to maintain their cultural integrity" (p. 476). Third, CRP emphasizes cultivating students' critical abilities "to recognize, understand, and critique current and social inequities" (p. 476). ES has strong parallels to CRP because it centers experiences and narratives of people of color, honors their cultural assets, develops strong familial relationships between students and teachers, and provides students with tools to critique inequality (Tintiango-Cubales et al., 2015). In addition, ES places a unique emphasis on acting to eliminate systemic oppression (Banks 2020; Cuahutin 2019; Sleeter 2011; Sleeter and Zavala 2020; Tintiangco-Cubales et al. 2015; Tintiangco-Cubales et al. 2019). In this way, ES harnesses CRP and is explicitly anti-racist in its design.

Dee and Penner $(2017 ; 2019)$ discuss how CRP, and by extension ES, can be understood within other social-scientific traditions. For example, several social-psychological experiments conducted in the field find positive academic effects of brief student-level interventions that shape identities in the schooling environment. These include forewarning students about stereotypes (Johns et al. 2005), affirming students' personal values (Cohen et al., 2006), promoting social belongingness in school (Walton and Cohen 2011), and emphasizing both the capacity to learn (Yeager et al. 2019) and external attributions for their life challenges (e.g, Ben-Zeev et al., 2005). Dee and Penner (2017) note ES resembles an unusually intensive psychological intervention because it includes elements of all these approaches (e.g., affirming values, forewarning about stereotypes), targets them to students transitioning to a new school, and delivers them on a sustained year-long basis. Furthermore, because ES is a classroom-level initiative, it may promote the supportive environments that are important for the successful replication of student-level interventions (Yeager and Walton 2011).

Long-standing sociological (e.g., Cooley, 1902; Du Bois 1903) and, more recently, economic (Akerlof and Kranton, 2002) perspectives on social identity also provide closely related conceptual frameworks for understanding ES. In general, these literatures have stressed how one's social identity can have important behavioral consequences. For example, the ground-breaking work of DuBois (1903) introduced the term "double consciousness" to explain the defining and burdensome "strife" marginalized people can experience when they simultaneously understand both their self-worth and the contrary perceptions of a racist environment. Motivated by this observation, Dee and Penner (2019) adapted a simple social-identity model (Akerlof and Kranton, 2002), which showed that experiencing school as a prejudiced environment can result in reduced academic engagement. These frameworks also indicate how ES and other CRP-aligned initiatives can attenuate this dynamic and increase the engagement of marginalized students by promoting belongingness, affirmation, and high expectations within otherwise alienating schooling environments.

The motivation and design of ES courses also has strong parallels with several conceptual frameworks from the field of community psychology. For example, critical consciousness theory likewise underscores the importance of promoting social analysis so that youth develop awareness of how social injustice operates and use that understanding to advocate for structural political and economic reform (Watts et al., 2011). Similarly, empowerment theory (e.g., Zimmerman, 2000) emphasizes self-determination through approaches the privilege concrete goal-oriented strategies for affecting social change. Lastly, theories of sociopolitical development extend these conceptualizations by positing that individuals must develop the appropriate knowledge, analytic and emotional capacity of both individual-specific and systemic-level oppression to engage in effective political activism (Watts et. al., 1999; Watts et al., 2003). These supporting theories highlight the theoretical basis for a well-designed and implemented ES course to catalyze transformative change. 
An extensive empirical literature on ES has stressed its capacity to catalyze school engagement and learning among students who have historically experienced academic environments as hostile and unwelcoming spaces (Banks 2020; Cuautin et al. 2019; Tintiangco-Cubales et al. 2015; Sleeter 2011; Sleeter and Zavala 2020). However, most of this evidentiary base relies on close qualitative or descriptive assessments of small numbers of teachers and schools (Belgrave et al. 2000; Cammarota 2007; Lewis, Sullivan, and Bybee 2006; Lewis et al. 2012; McCarty and Lee 2014; San Pedro 2015; Sleeter 2011; Wiggan and Watson-Vandiver 2019). Only two studies complement this literature with larger-scale quantitative evidence. Cabrera et al.(2014) find that voluntary student participation in Tucson's Mexican American Studies (MAS) program is positively correlated with the probability of high-school graduation. Using a regression-discontinuity (RD) design, Dee and Penner (2017) provide causal evidence on the academic effects of SFUSD's grade-9 ES course. This quasi-experimental study leveraged a unique institutional rule: several SFUSD high schools made a default assignment of rising grade-9 students to the pilot ES course if they had a grade-8 GPA below 2.0. Inferences based on this discontinuous assignment rule indicated that the encouraged students were more likely to take the ES course and had substantial improvements in important, short-term outcomes (i.e., attendance, GPA, and credits earned at the end of $9^{\text {th }}$ grade).

Though the existing evidence suggest ES courses have positive effects on students' academic outcomes, there is no causal evidence on longer-term effects. It is reasonable to suspect that the shortterm gains of the grade-9 ES course (Dee and Penner, 2017) may dissipate as soon as students return to conventional academic programs and environments. In some contexts, researchers have observed the "fade out" of effective educational interventions on academic outcomes (e.g., Chetty et al., 2011; Deming, 2009; Gibbs, Ludwig, and Miller, 2011; Lipsey, Farran, and Durkin, 2018), while in others they persist into early adulthood (Cortes, Goodman, and Nomi, 2015). Whether ES courses have longer-term effects is an open empirical question that depends on multiple factors. For example, ES courses may have sustained or even growing effects if they catalyze reinforcing processes of academic motivation, engagement, and success that are sustained by supportive learning environments (e.g., high-quality teachers, engaging curricula, supportive school environments). However, the longer-term impact of an ES course may also depend on whether the protection it affords students at a vulnerable time of transition and identity formation (e.g., $9^{\text {th }}$ grade), gives them a sense of purpose, coping mechanisms, and tangible skills with which to navigate a new school environment.

\section{Data}

We use the focal sample examined by Dee and Penner (2017). It consists of five unique schoolyear cohorts of $9^{\text {th }}$-grade students in SFUSD over three consecutive years AY2011-2012 through AY2013-2014 (N=1,405). We focus on these specific cohorts because their schools used a discontinuous assignment rule, automatically assigning $9^{\text {th }}$ graders to the ES course if their grade- 8 GPA was below 2.0. ${ }^{2}$ This assignment rule forms the basis for the regression-discontinuity design we describe in the next section.

We acquired longitudinal data on these students from three broad sources. First, SFUSD's administrative files include a variety of baseline traits for these students as well as data on their progression through high school. Second, to measure high-school graduation, we complement SFUSD's administrative data with statewide data from the California Longitudinal Pupil Achievement

\footnotetext{
2 Students could opt out of the ES course and choose another elective by speaking with a counselor. We note that, following Dee \& Penner (2017), this sample excludes students with missing or outlier values for grade-8 GPA (i.e., a perfect 4.0 or a value less than 1.25), the assignment variable in this RD design.
} 
Data System (CALPADS). And, third, we measure college matriculation using matched student-level data from the National Student Clearinghouse (NSC).

The baseline data include binary indicators for sex and whether the student was Black, Hispanic/Latino, Asian or White. Additional baseline (i.e., grade 8) covariates include their attendance rate, binary indicators for special education status, English Learner (EL) status, and having been suspended. These covariates also include the assignment variable used to determine ES encouragement (i.e., grade 8 GPA excluding physical education), centered at 2.0. We create a binary indicator identifying the "intent to treat" (ITT): whether the student had a GPA below 2.0. SFUSD's transcript data also allow us to identify students who took the ES course in $9^{\text {th }}$ grade.

Table 1 provides the summary statistics for our sample. The demographic traits of these students parallel the school district's distinctive diversity. Just over 60 percent of our sample identify as Asian compared to 5 percent of students nationally. Hispanic/Latino students comprise 23.1 of our sample, similar to the 27 percent enrolled nationally in K-12 schools. Black students in our sample, 6.3 percent, are underrepresented compared to 15 percent of public-school students nationally (U.S. Department of Education, 2019). Female students comprise only 41.7 percent of our sample, due to their higher representation among students excluded for having a perfect 4.0 eighth-grade GPA and their disproportionate enrollment in non-ES pilot, selective magnet schools. Because our study sample includes schools that opted into the ES pilot for the purpose of raising student achievement of academically lower-performing students, our sample includes students that, on average, had lower grade- 8 test scores, were more likely to be Latinx, and to be receive supports for documented disabilities. $^{3}$ A small portion of the sample, 8.3 percent, had a grade-8 GPA below 2.0 while 12.7 percent ultimately enrolled in the grade-9 ES course.

We examine several outcome variables, including one pre-registered confirmatory measure: high-school graduation. Because SFUSD's administrative records may not consistently track the educational attainment of the students who left the District, our measure relies instead on CALPADS data that identify whether a student has graduated (or dropped out) from any publicly administered high school (e.g., public, charter, etc.) in the state of California. Using the CALPADS data (and complementing it with NSC data), the completion status for 76 students out of the original 1,405 is unrecorded. ${ }^{4}$ Our preferred approach characterizes students as high-school graduates those who were meeting district-defined credit and course benchmarks for the districts high school graduation requirements. In Appendix 1, we report versions of our main RD results using several different measures and find similar effects. The vast majority of the remaining 76 students, particularly those near the IT'T threshold, are highly likely to be missing from the statewide data on high-school completers because they dropped out of high school. ${ }^{5}$ Studies based on similar administrative data (e.g., Heller et al, 2017) often identify such students as dropouts. We report results based on this approach in Appendix Table 1.

\footnotetext{
${ }^{3}$ While our study sample is distinct, we find no differences in student baseline test scores, racial/ethnic identification, sex, grade- 8 attendance or participation in English Language or Special Education programming at the 2.0 GPA assignment threshold for encouragement in ES enrollment (See Appendix Table 8).

${ }^{4}$ Most of this missingness is due to the statewide data on high-school graduates. Using the NSC enrollment data, we could confidently identify only 3 additional students as high-school graduates. These students enrolled seamlessly (i.e., the summer or fall after their expected high school graduation date) in a 4-year institution. We chose not to categorize students who enrolled in 2-year colleges as high school graduates because students in our sample often enrolled in California Community Colleges which do not require a high school diploma for individuals aged 18 and older. All students in our sample meet the age threshold and therefore 2-year postsecondary enrollment is unreliable for imputing high school graduation.

${ }^{5}$ Interestingly, the patterns in this missingness foreshadow this study's main finding. Auxiliary RD regressions indicate that students with grade-8 GPAs below 2.0 (i.e., ITT = 1) are more likely than students just above the threshold (ITT = $0)$ to appear in the statewide records on high school graduates.
} 
However, it is possible that some of these 76 students actually graduated from high school after switching to a private school or moving out of state. To examine the empirical relevance of this measurement concern, we also implement two more conservative approaches to identifying the educational attainment of students who do not appear in the statewide graduation files (or the NSC data). Under the first approach, we characterized as high-school graduates any students who were on track for graduation at the time they were no longer observed in the data $(n=15)$. This on-track measure utilizes credit accumulation and specific course completion requirements (i.e., English 1) that students are expected to meet each semester of high school. For example, on-track students must accumulate at least 30 credits their first semester of high school and earn five credits in math, English and Physical Education. SFUSD defines benchmarks for each semester of high school based on the District's high school graduation requirements. This is the main measure of high-school graduation used in our analysis. Under a second approach, we instead identified as high-school graduates those students $(\mathrm{n}=28)$ who were at least moderately on track for graduation at the time they no longer appeared in the administrative data (i.e., no more than one semester behind progress towards graduation). In Appendix Table 1, we report versions of our main RD results using all of these slightly different measures and find that the results are quite similar.

We also examine several exploratory outcome measures that capture high-school persistence as well as postsecondary enrollment. Our persistence measures include binary indicators for enrollment in SFUSD one, two, and three years after the grade-9 intervention year. A student is defined as enrolled when they have transcript records (i.e., course enrollment) and attendance records for at least one semester in a given school year. We also examine attendance rates and credits earned during each of these years, conditional on enrollment in SFUSD. These measures capture student persistence and are standard proxies for behavioral engagement in school (Allensworth \& Easton 2007; Balfanz et al. 2007). The vast majority of students in our sample remained enrolled in the district in the first year after they entered ninth grade (i.e., 97.4 percent). Enrollment in the school district decreased by approximately 2-3 percentage points in years three and four, to 94.9 and 92.8 percent, respectively. Attendance also decreases throughout high school with the largest decrease occurring between the third and fourth year of high school (i.e., from 93 to 91 percent) but, on average, remains over 90 percent throughout high school. The last measure we examine is credits earned. Students are required to earn 220 credits to graduate. The average student who remains enrolled in the school district earns over 230 credits by the end of their fourth year of high school, signaling that the majority of enrolled students meet the credit requirements for high school graduation.

Our final set of measures derive from postsecondary enrollment data from the NSC. These data are available for all students, regardless of district enrollment throughout the study period. Similar to national statistics, 69.5 percent of our sample enroll in postsecondary education (i.e., either a 2 or 4-year institution) immediately after high school (US Department of Education 2019). We also examine a second measure of postsecondary enrollment based on data a full year after on-time graduation (and 6 years after first participating in the ES course). On average, this enrollment measure decreases slightly to 68.1 percent.

\section{Methods}

We examine the longer-run effects of the ES course in a regression-discontinuity (RD) design based on SFUSD's assignment rule to identify the rising $9^{\text {th }}$ graders who were encouraged to take the course. The RD specification we estimate effectively compares the conditional outcomes of students with a grade- 8 GPA just below 2.0 (i.e., ITT=1) to students whose grade-8 GPA placed them just above this threshold (i.e., ITT=0). Specifically, we estimate the parameters of the following equation: 


$$
Y_{i s t}=\alpha+\beta I\left(G_{i s t}<0\right)+f\left(G_{i s t}\right)+\lambda \boldsymbol{X}_{i s t}+\eta_{s t}+\varepsilon_{i s t}
$$

where $Y_{i s t}$ is a student-level outcome (e.g., high school graduation) for student $i$ in school $s$, and in year $t$. The assignment variable, $G_{i s t}$, is the grade-8 GPA centered at 2.0. We create a binary indicator for the ITT, $I\left(G_{i s t}<0\right)$, that is equal to one for students whose GPA is less than 2.0 (and zero otherwise). Thus, the parameter $\beta$, represents the discontinuous change in outcomes when students are encouraged to take the ES course, conditional on $f\left(G_{i s t}\right)$, a smooth function of the assignment variable. We also present results based on introducing controls for a vector of studentlevel baseline traits (i.e., $\boldsymbol{X}_{i s t}$ ) and fixed effects specific to each unique school-year cohort (i.e., $\eta_{s t}$ ). The term, $\varepsilon_{i s t}$, is a mean-zero error term and all our models rely on robust (i.e., Eicker-Huber-White) standard errors.

Intuitively, an $\mathrm{RD}$ design like this identifies causal effects by leveraging the "as good as randomized" variation (Lee and Lemieux, 2010) in whether a student was just above or just below an arbitrary threshold that implies a sharp contrast in treatment. However, the causal warrant of such an $\mathrm{RD}$ design turns on several critical assumptions. In recent years, the available research guidance (e.g., What Works Clearinghouse, 2020) has provided increasingly standardized recommendations for several types of ancillary evidence that critically examine these key assumptions. First, we note that, using these data, Dee and Penner (2017) present both graphical and statistical evidence of a large and discontinuous change at the relevant threshold in the probability of enrolling in the $9^{\text {th }}$-grade ES course. Specifically, RD estimates indicate that the probability of taking the course increases by a large and statistically significant amount (i.e., 27 percentage points) for students with grade-8 GPAs below the 2.0 threshold. $^{6}$

A second key consideration is the "integrity" of the assignment variable in an $\mathrm{RD}$ design (What Works Clearinghouse, 2020). The institutional knowledge of this process (e.g., the use of a predetermined variable for a $9^{\text {th }}$-grade assignment) suggests that the assignment variable could not be easily manipulated in ways that would confound the internal validity of the RD design. Consistent with this assumption, we find that a density test (Cattaneo, Janson and Ma, 2020) does not reject the null hypothesis that the number of observations is smoothly distributed around the threshold. ${ }^{7}$ Third, because we observe our key outcome measure for the full sample, differential attrition is not an issue. Some of our exploratory outcome measures (i.e., attendance and credits earned) are only observed for students who remained enrolled in SFUSD. However, we present RD evidence that the probability of being enrolled in SFUSD is balanced around the ITT threshold for each of the years after entering $9^{\text {th }}$ grade, which suggests that this form of sample attrition is not differential.

An important, fourth source of evidence on the validity of an $\mathrm{RD}$ design concerns the balance of outcome-relevant, baseline covariates. If the variation in students' position around the RD threshold is "as good as randomized," we would expect that baseline student covariates do not exhibit discontinuities at the IT"T threshold. Consistent with this, auxiliary RD regressions in which the baseline covariates used in this study are the dependent variables indicate that the covariate differences

\footnotetext{
${ }^{6}$ We also present additional evidence consistent with the "exclusion restriction" (i.e., that the contrast at this threshold does not imply outcome-relevant determinants other than ES take-up). In Appendix 6 and 7 we find that this threshold has small and statistically insignificant effects on outcomes among students at the SFUSD high schools which did not offer the ES course.

${ }^{7}$ Unrestrictive histograms are consistent with this assumption as well but also indicate that values of the grade-8 GPA clearly cluster into "heaps" at integer and half-integer values. To investigate the possibility of "heaping-induced bias," Dee and Penner (2017) examine their results excluding observations with values of the assignment variable at these heaps (Barreca et al., 2016). We conduct a similar exercise and find similar RD estimates in specifications that exclude these observations.
} 
at the ITT threshold are small and statistically insignificant (see Appendix Table 2). ${ }^{8}$ A closely related source of evidence is to examine graphically the relationship between the assignment variable and the outcomes. This graphical evidence provides both unrestrictive evidence on the possible effect of the ITT and an opportunity to assess whether any discontinuities are apparent at other thresholds that did not define a treatment contrast.

A fifth and final class of evidence on the validity of an RD design involves exploring the robustness of the results to alternative ways of modeling the functional form of $f\left(G_{i s t}\right)$. Our baseline specification conditions on linear splines of $G_{i s t}$, allowing the assignment variable to have distinctive slopes above and below the ITT threshold. However, we also show our key results in specifications that add quadratic splines. Critically, we also show the results from nonparametric local linear regressions which only use the data from increasingly tight bandwidths around the ITT threshold. We also present our key results graphically both using the full sample of data as well as the subset of data in a tighter bandwidth (i.e., 1 standard deviation of grade-8 GPA) around the IT'T threshold. Further, we show the results of specifications that use algorithmically chosen bandwidths (Imbens \& Kalyanaraman 2012; Calonico et al. 2020) and triangular kernel weights, which upweight observations that are closer to the ITT threshold (Fan and Gijbels, 1996).

We conclude with two important observations about the generalizability (i.e., "external validity") of the RD estimates we report. First, a well-known and intuitive caveat about RD designs is that, because they rely on variation close to a specific threshold, the resulting estimates may not generalize to students whose baseline traits made them distant from this threshold. For example, because our research design leverages an assignment rule that encouraged academically at-risk students to take the ES course, our results do not necessarily speak to the impact of the ES course for students who had a high grade-8 GPA.

A second external-validity issue relevant to this research design concerns the possible heterogeneity in the treatment effects we report. Our key RD estimates identify the reduced-form impact of the encouragement to take the ES course (i.e., ITT=1). However, as often occurs in randomized experiments, we have partial compliance with this ITT. That is, in this "fuzzy" RD application, the treatment status of some individuals does not comply with their ITT. Some students (i.e., "always takers") take the ES course even when their grade-8 GPA is at or above 2.0 (i.e., ITT=0). And some students (i.e., "never takers") do not take the ES course even when their grade-8 GPA is below 2.0 (i.e., ITT=1). The "local average treatment effect" (LATE) theorem (Imbens and Angrist, 1994) states that, in the presence of such partial compliance and treatment heterogeneity, approaches like ours identify causal effects defined specifically for the subgroup of "compliers" (i.e., those who take the ES course when IT'T $=1$ and do not when ITT=0). As an intuitive example of why this heterogeneity might reasonably exist in this context, suppose the type of student who would always take the ES course has positive but unobserved motivations and experiences that make the possible academic benefits of the ES course less relevant for them. Then, we would expect the academic benefits of the course to be larger for "compliers" than for "always takers." We test for this heterogeneity by presenting results from a procedure recently introduced by Bertanha and Imbens (2020). ${ }^{9}$

Lastly, there are two unique concerns related to this study setting that the effects measured in this study may be attributed to other factors occurring at the 2.0 GPA threshold. As noted previously, the district utilized an early warning indicator to identify students at-risk of high school dropout and target them with additional academic supports, raising concerns that the results are indicative of effective EWI interventions and not ES eligibility. Dee and Penner (2017) estimate auxiliary

\footnotetext{
${ }^{8}$ Our main specifications are unchanged when we add these test score controls to our main results (Appendix Table 3 ).
}

${ }^{9}$ We describe this procedure and present the results in more detail in our supplementary materials. 
regressions at the EWI threshold in schools that did not pilot ES and found null effects indicating that EWI supports did not have meaningful impacts on student outcomes. We repeat this falsification exercise with our high school attainment and engagement outcomes and similarly conclude that there is no evidence that district EWI supports increased student outcomes. ${ }^{10}$ A secondary concern relates to the fact that only four teachers taught ES to all of the cohorts in our sample. We may be concerned that the positive outcomes are due to particularly effective teachers rather than the ES course. However, when Dee and Penner (2017) examined the outcomes of these teacher's non-ES students using a teacher fixed-effect estimation strategy, they found the teachers were not different from the regular distribution of district social studies teachers. We follow up on these results and estimate the longer-term effects by excluding the students of the one teacher who exhibited consistently large fixed effects in Dee and Penner (2017) (i.e., indicating above average effects on student outcomes), and we find that the positive effects for ES-eligible students remained.

\section{Enrollment, Attendance, and Credits}

\section{Results}

We begin by presenting visual and parametric RD evidence on how assignment to the grade9 ES course influenced measures of high-school persistence and engagement across each of the three subsequent years. Our study pre-registration characterized this analysis as exploratory. Table 2 presents parametric estimates of the effect of ES eligibility on enrollment in SFUSD, as well as attendance and credits earned conditional on enrollment. We present these exploratory results both for the full analytic sample (i.e., $\mathrm{N}=1,405$ ) and the subset of the sample within one standard deviation of the IT'T threshold (i.e., within 0.67 eighth grade GPA points of 2.0).

The results in Table 2 indicate that ES eligibility did not have statistically significant effects on subsequent SFUSD enrollment. However, these comparative results, though statistically imprecise, suggest that a discontinuity in enrollment did grow over time. By year 4, students with grade-8 GPAs below 2.0 were roughly 8 percentage points more likely to be enrolled than students to the right of the threshold (Table 2, column 4, p-value $=0.24$ ), which is supported by graphical evidence from Figure 1 indicating that students assigned to take the ES course were more likely to remain enrolled over time.

In contrast, the results in Table 2 indicate that ES eligibility (i.e., ITT=1) generated large and statistically significant increases in student attendance in all three post-treatment years. The estimated increases based on the full sample (i.e., 6 to 7 percentage points) are similar to the grade- 9 effects reported by Dee and Penner (2017). The estimated increases based only on students within a 1 SD bandwidth are somewhat larger (i.e., 10 to 12 percentage points). These results, which are also supported by a discontinuous increase in student attendance at the ES eligibility threshold presented in Figure 1, suggest that the ES course led to sustained, and possibly growing, improvements in students' behavioral engagement throughout high school.

However, the successful progression through high school also depends on the successful accumulation of course credits. A semester-long course in the district typically confers five credits and students commonly enroll in six to seven courses (i.e., 30 to 35 credits) per semester. During this period, SFUSD employed a 220 -credit minimum in order to graduate. In the first-year study, ESencouraged participants earned just over six additional credits than their ineligible peers (p. 146, Dee and Penner 2017). Our full-sample results in Table 2 suggest that the credit gains among students with

\footnotetext{
${ }^{10}$ In Appendix Tables 4 and 5 we provide estimates of the "placebo" effect of EWI identification at schools that did not implement ES courses and find null impacts for high school engagement (Appendix Table 4) and educational attainment (Appendix Table 5).
} 
ITT $=1$ were sustained and possibly grew over the next three years (i.e., 8 to 15 credits). These estimated gains are noticeably larger in the local linear regressions (LLR) based on the 1 SD sample proximate to the threshold (i.e., 17 to 31 credits), and are supported by the graphical evidence in Figure 1. These graphs also illustrate how these gains are salient to students' likelihood of graduating from high school. In their fourth year, students on the ITT $=0$ side of the threshold (panel I in Figure 1) had on average only 200 credits (i.e., roughly 20 credits short of the amount required for graduation). However, students just to the left of the threshold (i.e., those encouraged to take the ES course) were, on average, substantially closer to the number of credits required for high-school graduation.

\section{Educational Attainment}

Our main confirmatory analysis examines the effect of the encouragement to take the ES course on high-school graduation. We report the key parametric results based on the full-sample in the top panel of Table 3. These results indicate that ES eligibility generated substantial gains in high school graduation rates (i.e., from 16 to 19 percentage points). The graphical evidence in Figure 2 supports these estimates and shows a substantial discontinuous jump in high school graduation at the ES-eligibility threshold. Similar to our measures of high school persistence and engagement, estimates based on a narrower bandwidth within 1 SD of the threshold are larger (i.e., 25 percentage points) than in the full sample.

These gains in high school graduation, however, may not translate to postsecondary enrollment given that ES eligibility targeted students with lower achievement in middle school. In the middle and bottom panels of Table 3, we present parametric estimates for postsecondary enrollment in years 5 and 6 . These exploratory results suggest that the encouragement to take the ES course led to a large increase in college enrollment (i.e., 10 to 16 percentage points). However, in results based on the full sample, these point estimates are not statistically significant at conventional levels (Table 3, column 3, $\mathrm{p}=0.16$ ). In Figure 2 we provide graphical evidence of the relationship between postsecondary enrollment and ES-eligibility. ${ }^{11}$ These graphs provide suggestive evidence of increased postsecondary enrollment at the ES threshold. Notably, our LLR estimates in Appendix Table 1 (e.g., utilizing observations within $1 \mathrm{SD}$ of the threshold) also indicate that there was a positive and statistically significant increase in postsecondary enrollment (i.e., 25 to 26 percentage points) at the ITT threshold.

In general, these results indicate that ES course-induced gains in high-school graduation were large and possibly extended to increased postsecondary enrollment. We explore the robustness of these key findings in several alternative specifications. A uniquely salient concern is whether our RD results reflect the misspecification of the functional form that relates grade- 8 GPA to these longerrun outcomes. The visual results in Figure 2 provide unrestrictive evidence that suggests this is not a concern. However, we also complement this with the results of several different approaches to modeling $f\left(G_{\text {ist }}\right)$.

Table 4 presents the key results based on these specifications and for each measure of educational attainment. The first row of Table 4 presents the baseline results from Table 3 followed by estimates with quadratic polynomials and increasingly restrictive bandwidths. With respect to our core confirmatory inference about high-school graduation, we see that the main results in Table 3 are quite robust to a range of bandwidth restrictions and estimation choices (e.g., weighting with triangular

\footnotetext{
${ }^{11}$ We also estimate these results using different measures of postsecondary enrollment (i.e., 2-year only, 4-year only) and do not find substantially different results. We can view the specific institutions students near the ITT threshold enrolled in and the increases in postsecondary enrollment are driven by broad-access institutions (e.g., California State Universities and community colleges).
} 
kernels). ${ }^{12}$ In fact, when using data from tighter bandwidths around the threshold, the estimated effects of the IT'T on high-school are often noticeably larger (i.e., 23 to 30 percentage points). With respect to our exploratory results regarding college enrollment, the results in Table 4 consistently suggest large, positive effects. However, these results are not always statistically significant.

We also explored the robustness of our key results to alternative definitions of high-school graduation. Our preferred measure complements the state-confirmed data with data from the National Student Clearinghouse (NSC) and, for a small number of observations, an imputation based on their on-track status when they attritted from the data (i.e., row 3 in Appendix Table 1). We show in Appendix Table 1 that our key results are quite similar when using alternative definitions of highschool graduation (e.g., only using state and NSC data).

Finally, we assess whether any discontinuities in outcomes are apparent at other thresholds that did not define a treatment contrast and find no evidence of effects when conducting "placebo tests." We conduct these robustness checks with two distinct samples. First, we use the main study sample and estimate the effect at GPA thresholds above and below 2.0 (i.e., placebo thresholds). Second, we utilize a sample of SFUSD students at high schools that did not offer ES courses and estimate the effect of being eligible for district EWI supports (e.g., tutoring) for lower-performing students and find no evidence of impacts (See Appendix Tables 4 and 5). Lastly, we follow Grembi and coauthors (2016) and estimate a "difference in discontinuity" design where we combine the ES pilot and the non-ES school samples and estimate a RD model that differences out the corresponding threshold effects of the non-ES pilot school sample (See Appendix Table 6). These three supplementary analyses support the conclusion that encouragement to enroll in the grade-9 ES course is responsible for the documented positive effects in increased high school engagement and educational attainment.

\section{Heterogenous Treatment Effects}

The original study found that there were consistently positive effects across student racial and ethnic groups and for both male and female students. While the results indicated that ES-eligibility was not harmful to any one demographic group, Dee and Penner (2017) found that some students, particularly males and Hispanic/Latino students experienced larger positive effects compared to female and other racial and ethnic groups. In Appendix Table 7 we explore potential treatment heterogeneity using our high school persistence and engagement measures and in Appendix Table 8 we examine the effects on educational attainment.

Our subgroup specific effects of high school graduation indicate that all groups of students experienced gains. Both ES-eligible male and female students experienced positive and statistically significant gains in high school graduation, 15 and 23 percentage points, respectively (Appendix Table 8). Asian and Hispanic/Latino students demonstrated gains in high school graduation (i.e., 19 and 11 percentage points) though the estimates for Hispanic/Latino students are statistically imprecise due to the lower representation of Hispanic/Latino students in our sample (i.e., 23 percent or 324 observations). The scale of this multi-school pilot results in a relatively small sample size and this limits our ability to examine heterogeneity in treatment effects for some racial/ethnic groups (i.e., whites and Blacks).

\footnotetext{
12 We include the results from algorithmically chosen bandwidths (Imbens \& Kalyanaraman 2012, Calonico et al. 2014). We also note that the estimated impact on high-school graduation becomes statistically insignificant in only two instances: when conditioning on a quadratic of the assignment variable and when using the data (i.e., 126 out of 1,405 observations) in the bandwidth based on the Calonico et al. (2014) procedure. In both cases, the point estimate is largely unchanged but there is a substantial loss of statistical precision.
} 
Another policy-relevant form of treatment heterogeneity is that implied by the LATE Theorem (Imbens and Angrist, 1994). That is, in applications like ours where there is only partial compliance with the ITT, the resulting causal estimate may only be relevant for the sub-population of "compliers" (i.e., those who take the ES course when ITT=1 and do not when ITT=0). For example, it may be that the ES course has more impact among those who only take it when encouraged than among the "always takers" who take the course regardless of their ITT status. We subset the sample by ES uptake and estimate auxiliary RD regressions (see Appendix Tables 9 and 10) for our high school persistence and educational attainment measures. The key insight is that the contrast for ES enrollees (i.e., $\mathrm{ES}=1$ ) compares compliers and always-takers (i.e., ITT=1) with always-takers (ITT=0) above the assignment threshold. We find uniformly positive effects for measures of high school engagement and graduation. This suggests that the ES course was uniquely helpful for compliers, those students who enrolled in ES because their eighth grade GPA was below 2.0, whereas the ES course had no impact on those students who would have always enrolled in ES if it were offered. For those who do not enroll in ES (i.e., $\mathrm{ES}=0$ ), we compared never-takers (i.e., IT'T=1) with compliers and never-takers (i.e., ITT=0). We find no effects for these students which suggests that students with low-eighth grade GPA's who requested their counselor switch them from ES to health or a college readiness elective had underlying characteristics (e.g., high motivation etc.) that positioned them for better outcomes. These findings suggest that ES may be less effective for students who would decline (i.e., never-takers) or insist (i.e., always-takers) on enrolling in ES.

\section{Conclusion}

This study presents evidence, based on a pre-registered regression-discontinuity design, that participation in a grade-9 ES course significantly increased the probability of graduating from high school for academically lower-performing students. We also find complementary evidence that taking the ES course increased measures of behavioral engagement in school (i.e., enrollment, attendance, and earned credits) and may have increased the likelihood of attending college. Our findings are consistent with a long-standing and influential body of qualitative evidence on the educational impact of ES courses and culturally relevant pedagogy, more generally, and provides credibly causal evidence consistent with the prior evidence of a positive association between ethnic-studies participation and high-school graduation (Cabrera et al., 2014).

Our results also highlight that ES courses can provide students with an opportunity to engage with critical, anti-racist content in a rigorous college preparatory course that promotes academic success. We also note that these results are consistent with conceptual frameworks from community psychology as well as recent experimental evidence on the educational benefits of targeted socialpsychological interventions that support students' sense of identity and belongingness in school environments. That is, ES courses resemble unusually intensive, multi-faceted, and sustained socialpsychological interventions, particularly for students from historically marginalized groups. For example, ES courses give students an opportunity to learn about, appreciate and celebrate their origins, as well as foreground the numerous contributions of marginalized communities to American history and social life (i.e., school belongingness and values affirmations). Furthermore, the explicit discussions of power, structural racism, stereotypes, and hegemony prime student awareness of the many structural social hurdles they face (i.e., stereotype forewarning and external attribution).

Targeting the ES course to $9^{\text {th }}$ graders may also be a critical design feature. Social-psychological interventions typically begin at the start of the academic year when students' social identities in the stylized and evaluative context of classrooms are thought to be at their most malleable. By engaging rising $9^{\text {th }}$ graders just as they entered their "make or break" year (Philips, 2019) in a new school 
environment, the ES course appears to have disrupted recursive cycles of poor attendance and academic disengagement that contribute to the risk of eventually dropping out.

Notably, we observe these positive effects among different subgroups of students defined by their racial/ethnic and gender identities. However, two dimensions of heterogeneity in the educational impact of the ES course merit special note. The first involves the potential localness of estimates based on this regression-discontinuity design (i.e., an intent to treat based on a low GPA in $8^{\text {th }}$ grade). Because this research design leverages the targeting of the course to academically at-risk students, the resulting inferences may not generalize to students who had higher grade-8 GPAs and are at substantially lower risk of dropping out of high school. Second, using a technique recently introduced by Bertanha and Imbens (2020), we find evidence consistent with the hypothesis that the benefits of the ES course are lower among students who would always choose to take the course as well as among those who choose never to take the course when given an option.

Furthermore, the potentially considerable logistical challenges of fielding effective ES courses at scale and with a high degree of fidelity are also noteworthy. The SFUSD ES course examined in this study reflected several years of curriculum development tailored to the local context as well as corresponding professional development of a core group of self-selected educators who had access to institutional support (e.g., release-time for planning) and the guidance of external experts. Mandating the wide-scale availability of ES through policy without thoughtful curricular development and teacher training may not reproduce the educational gains we document here. However, we also note that an ES course is likely to be exceptionally cost-effective relative to other interventions that are effective in reducing dropout risk. That is because the introduction of an ES course is likely to be a reallocation of existing resources dedicated to staffing, curricular development, and teacher training. In contrast, other interventions effective at promoting high-school completion often require new and comparatively expensive out-of-class programming (e.g., cognitive behavioral therapy, Heller et al., 2017).

More generally, the results of this study comport with a research literature which suggests that the adoption of high-quality curricula is a relatively tractable lever for school reform (e.g., Whitehurst, 2009). However, the unique features of the ES course make a distinctive contribution to this literature. Specifically, it suggests the educational potency of pedagogies and content (i.e., anti-racist education) that allow students to experience belongingness and psychological integrity in school. The results presented here suggest that the educational effects of curricula and teaching practices that similarly support positive social identities in classrooms merit further scrutiny in the context of other academic subjects (e.g., math, science, and reading). 


\section{References}

Akerlof, G. A., \& Kranton, R. E. (2002). Identity and schooling: Some lessons for the economics of education. Journal of economic literature, 40(4), 1167-1201.

Allensworth, E. M., \& Easton, J. Q. (2007). What Matters for Staying On-Track and Graduating in Chicago Public High Schools: A Close Look at Course Grades, Failures, and Attendance in the Freshman Year. Research Report. Consortium on Chicago School Research.

Bailey, D., Duncan, G. J., Odgers, C. L., \& Yu, W. (2017). Persistence and fadeout in the impacts of child and adolescent interventions. Journal of research on educational effectiveness, 10(1), 7-39.

Balfanz, R., Herzog, L., \& Mac Iver, D. J. (2007). Preventing student disengagement and keeping students on the graduation path in urban middle-grades schools: Early identification and effective interventions. Educational Psychologist, 42(4), 223-235.

Banks, J. A. (2020). Series Forward. In C. E. Sleeter \& M. Zavala (Eds.), Transformative Ethnic Studies in Schools: Curriculum, Pedagogy, \& Research (pp. vii-xii). Teachers College Press.

Barreca, A. I., Lindo, J. M., \& Waddell, G. R. (2016). Heaping-induced bias in regression-discontinuity designs. Economic Inquiry, 54(1), 268-293.

Belgrave, F. Z., Chase-Vaughn, G., Gray, F., Addison, J. D., \& Cherry, V. R. (2000). The Effectiveness of a Culture and Gender-Specific Intervention for Increasing Resiliency among African American Preadolescent Females. Journal of Black Psychology, 26(2), 133-147.

Ben-Zeev, T., Fein, S., \& Inzlicht, M. (2005). Arousal and stereotype threat. Journal of Experimental Social Psychology, 41(2), 174-181.

Bertanha, M., \& Imbens, G. W. (2020). External validity in fuzzy regression discontinuity designs. Journal of Business \& Economic Statistics, 38(3), 593-612.

Bonilla, S., Dee, T. S., \& Penner, E. (2019, September 19). The longer-term effects of cultural relevance: evidence from an ethnic-studies curriculum. Open Science Framework Pre-Registration. Retrieved from osf.io/89mrt

Cabrera, N. L., Milem, J. F., Jaquette, O., \& Marx, R. W. (2014). Missing the (Student Achievement) Forest for All the (Political) Trees Empiricism and the Mexican American Studies Controversy in Tucson. American Educational Research Journal, 51(6), 1084-1118.

Calonico, S., Cattaneo, M. D., \& Farrell, M. H. (2020). Optimal bandwidth choice for robust biascorrected inference in regression discontinuity designs. The Econometrics Journal, 23(2), 192-210.

Calonico, S., Cattaneo, M. D., \& Titiunik, R. (2014). Robust nonparametric confidence intervals for regression-discontinuity designs. Econometrica, 82(6), 2295-2326.

Cammarota, J. (2007). A social justice approach to achievement: Guiding Latina/o students toward educational attainment with a challenging, socially relevant curriculum. Equity \& Excellence in Education, 40(1), 87-96.

Cattaneo, M. D., Jansson, M., \& Ma, X. (2018). Manipulation testing based on density discontinuity. The Stata Joumal, 18(1), 234-261.

Cattaneo, M. D., Jansson, M., \& Ma, X. (2020). Simple local polynomial density estimators. Journal of the American Statistical Association, (115)531, 1449-1455. Retrieved from https://doi.org/10.1080/01621459.2019.1635480

Chetty, R., Friedman, J. N., Hilger, N., Saez, E., Schanzenbach, D. W., \& Yagan, D. (2011). How does your kindergarten classroom affect your earnings? Evidence from Project STAR. The Quarterly journal of economics, 126(4), 1593-1660.

Cohen, G. L., Garcia, J., Apfel, N., \& Master, A. (2006). Reducing the racial achievement gap: A socialpsychological intervention. Science, 313(5791), 1307-1310.

Cooley, C. H. (1902). Looking-glass self. The production of reality: Essays and readings on social interaction, 6, 126-128. 
Cortes, K. E., Goodman, J. S., \& Nomi, T. (2015). Intensive math instruction and educational attainment long-run impacts of double-dose algebra. Journal of Human Resources, 50(1), 108-158.

Cuauhtin, R. T. (2019). We have community cultural wealth!: Scaffolding Tara Yosso's theory for classroom praxis. In R. T. Cuauhtin, M. Zavala, C. E. Sleeter, \& W. Au (Eds.), Rethinking Ethnic Studies. Rethinking Schools.

de Novais, J., \& Spencer, G. (2019). Learning race to unlearn racism: The effects of ethnic studies course-taking. The Journal of Higher Education, 90(6), 860-883.

Dee, T. S., \& Penner, E. K. (2017). The causal effects of cultural relevance: Evidence from an ethnic studies curriculum. American Educational Research Journal, 54(1), 127-166.

Dee, T., \& Penner, E. (2019). My Brother's Keeper? The Impact of Targeted Educational Supports (No. w26386). National Bureau of Economic Research.

Deming, D. (2009). Early childhood intervention and life-cycle skill development: Evidence from Head Start. American Economic Journal: Applied Economics, 1(3), 111-34.

Du Bois, W. E. B. (1903). The souls of black folk: essays and sketches. Chicago, IL: A. G. McClurg \& Co.

Evers, Williamson M. "California Wants to Teach Your Kids That Capitalism is Racist," Wall Street Journal, July 29, 2019. Accessed at https://www.wsj.com/articles/california-wants-to-teachyour-kids-that-capitalism-is-racist-11564441342.

Fan, Jianqing, and Irene Gijbels. 1996. Local Polynomial Modelling and Its Applications. London; New York and Melbourne: Chapman and Hall.

Flannery, M.E. (2020). "Ethnic Studies Classes Growing in Popularity,” NEA Today, June 9, 2020. Access at https://www.nea.org/advocating-for-change/new-from-nea/ethnic-studies-classesgrowing-popularity on May 8, 2021.

Gecker, J. "California Ethnic Studies Debate: Whose Stories Get Told," Associated Press, March 25, 2021. Accessed at https://apnews.com/article/race-and-ethnicity-education-californiad4e28bba7b0c54fcd446ec456fa38e14.

Gibbs, C., Ludwig, J., \& Miller, D. L. (2011). Does Head Start do any lasting good? (No. w17452). National Bureau of Economic Research.

Heller, S. B., Shah, A. K., Guryan, J., Ludwig, J., Mullainathan, S., \& Pollack, H. A. (2017). Thinking, fast and slow? Some field experiments to reduce crime and dropout in Chicago. The Quarterly Journal of Economics, 132(1), 1-54.

Imbens, G. W., \& Angrist, J. D. (1994). Identification and Estimation of Local Average Treatment Effects. Econometrica, 62(2), 467-475.

Imbens, G., \& Kalyanaraman, K. (2012). Optimal bandwidth choice for the regression discontinuity estimator. The Review of economic studies, 79(3), 933-959

Johns, M., Schmader, T., \& Martens, A. (2005). Knowing is half the battle: Teaching stereotype threat as a means of improving women's math performance. Psychological Science, 16(3), 175-179.

Ladson-Billings, G. (1995). Toward a theory of culturally relevant pedagogy. American educational research journal, 32(3), 465-491.

Lewis, K. M., Sullivan, C. M., \& Bybee, D. (2006). An experimental evaluation of a school-based emancipatory intervention to promote African American well-being and youth leadership. Journal of Black Psychology, 32(1), 3-28.

Lewis, K. M., Andrews, E., Gaska, K., Sullivan, C., Bybee, D., \& Ellick, K. L. (2012). Experimentally evaluating the impact of a school-based African-centered emancipatory intervention on the ethnic identity of African American adolescents. Journal of Black Psychology, 38(3), 259-289.

Lipsey, M. W., Farran, D. C., \& Durkin, K. (2018). Effects of the Tennessee Prekindergarten Program on children's achievement and behavior through third grade. Early Childhood Research Quarterly, 45, 155-176. 
McCarty, T., \& Lee, T. (2014). Critical Culturally Sustaining/Revitalizing Pedagogy and Indigenous Education Sovereignty. Harvard Educational Review, 84(1), 101-124. https://doi.org/10.17763/haer.84.1.q83746nl5pj34216.

Nicol, D. J. (2013). Movement conservatism and the attack on ethnic studies. Race Ethnicity and Education, 16(5), 653-672.

Office of Learning Support and Equity/Humanities, Academics and Professional Development. (2009). Proposal to pilot a 9th grade Ethnic Studies course in the San Francisco Unified School District during the 2010-11 school year. San Francisco, CA: San Francisco Unified School District.

Phillips, E. K. (2019). The Make-or-break Year: Solving the Dropout Crisis One Ninth Grader at a Time. The New Press.

San Pedro, T. J. (2015). Silence as shields: Agency and resistances among Native American students in the urban Southwest. Research in the Teaching of English, 132-153.

SFUSD Ethnic Studies Curriculum Collective. (2012). Ethnic Studies Strategic Plan 2012-2013. San Francisco Unified School District.

Sleeter, C. E. (2011). The academic and social value of Ethnic Studies: A research review. Washington, D.C.: National Education Association Research Department.

Sleeter, C. E., Acuff, J. B., Bentley, C., Guzman Foster, S., Morrison, P., \& Stenhouse, V. (2019). Multicultural Education or Ethnic Studies? In R. T. Cuauhtin, M. Zavala, C. E. Sleeter, \& W. Au (Eds.), Rethinking Ethnic Studies. Rethinking Schools.

Sleeter, C. E., \& Zavala, M. (2020). Transformative Ethnic Studies in Schools: Curriculum, Pedagogy, and Research. Teachers College Press.

Tintiangco-Cubales, A., Kohli, R., Sacramento, J., Henning, N., Agarwal-Rangnath, R., \& Sleeter, C. (2015). Toward an ethnic studies pedagogy: Implications for K-12 schools from the research. The Urban Review, 47(1), 104-125.

Tintiangco-Cubales, A., Kohli, R., Sacramento, J., Henning, N., Agarwal-Rangnath, R., \& Sleeter, C. E. (2019). What is Ethnic Studies Pedagogy? In R. T. Cuauhtin, M. Zavala, C. E. Sleeter, \& W. Au (Eds.), Rethinking Ethnic Studies (pp. 20-25). Rethinking Schools.

U.S. Department of Education (2019) Digest of Education Statistics 2019. National Center for Education Statistics, Institute of Education Sciences, U.S. Department of Education. Washington, D.C

Walton, G. M., \& Cohen, G. L. (2011). A brief social-belonging intervention improves academic and health outcomes of minority students. Science, 331(6023), 1447-1451.

Watts, R. J., Diemer, M. A., \& Voight, A. M. (2011). Critical consciousness: Current status and future directions. New directions for child and adolescent development, 2011(134), 43-57.

Watts, R. J., Griffith, D. M., \& Abdul-Adil, J. (1999). Sociopolitical development as an antidote for oppression-theory and action. American journal of community psychology, 27(2), 255-271.

Watts, R. J., Williams, N. C., \& Jagers, R. J. (2003). Sociopolitical development. American journal of community psychology, 31(1-2), 185-194.

What Works Clearinghouse. (2020). What Works Clearinghouse Standards Handbook, Version 4.1. Washington, DC: U.S. Department of Education, Institute of Education Sciences, National Center for Education Evaluation and Regional Assistance. This report is available on the What Works Clearinghouse website at https://ies.ed.gov/ncee/wwc/handbooks.

Whitehurst, G. (2009). Don't Forget Curriculum. Brown Center Letters on Education. Brookings Institution, https://www.brookings.edu/research/the-challenges-of-curriculum-materials-as-areform-lever/.

Wiggan, G., \& Watson-Vandiver, M. J. (2019). Pedagogy of empowerment: student perspectives on critical multicultural education at a high-performing African American school. Race ethnicity and education, 22(6), 767-787.

Yeager, D. S., \& Walton, G. M. (2011). Social-psychological interventions in education: They're not magic. Review of educational Research, 81(2), 267-301. 
Yeager, D. S., Hanselman, P., Walton, G. M., Murray, J. S., Crosnoe, R., Muller, C., ... \& Paunesku, D. (2019). A national experiment reveals where a growth mindset improves achievement. Nature, 16.

Zavala, M., Cuauhtin, R. T., Au, W., \& Sleeter, C. E. (2019). The Movement for Ethnic Studies: A Timeline. In R. T. Cuauhtin, M. Zavala, C. E. Sleeter, \& W. Au (Eds.), Rethinking Ethnic Studies (pp. 9-11). Rethinking Schools.

Zimmerman, M. A. (2000). Empowerment theory. In Handbook of community psychology (pp. 43-63). Springer, Boston, MA. 

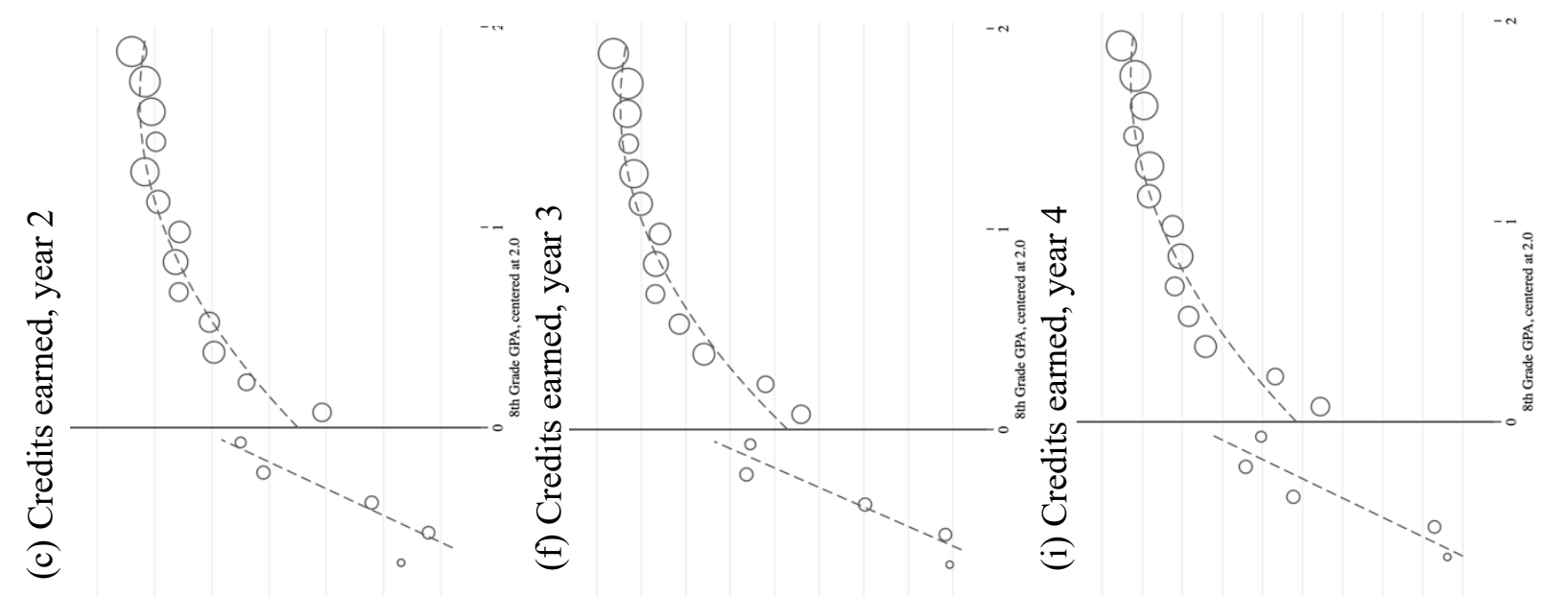

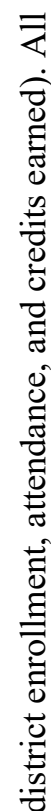
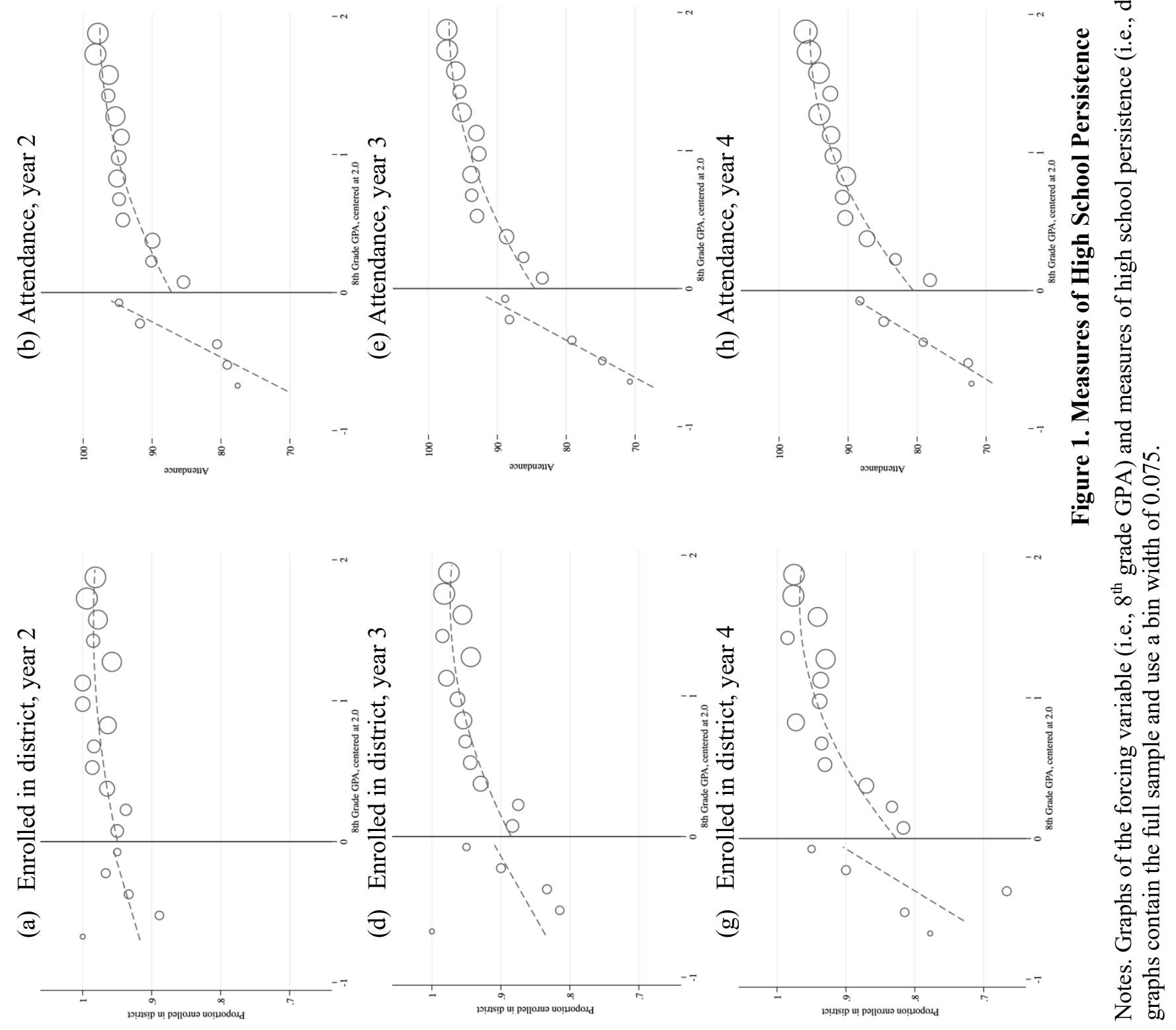
(a) High school graduation, full sample

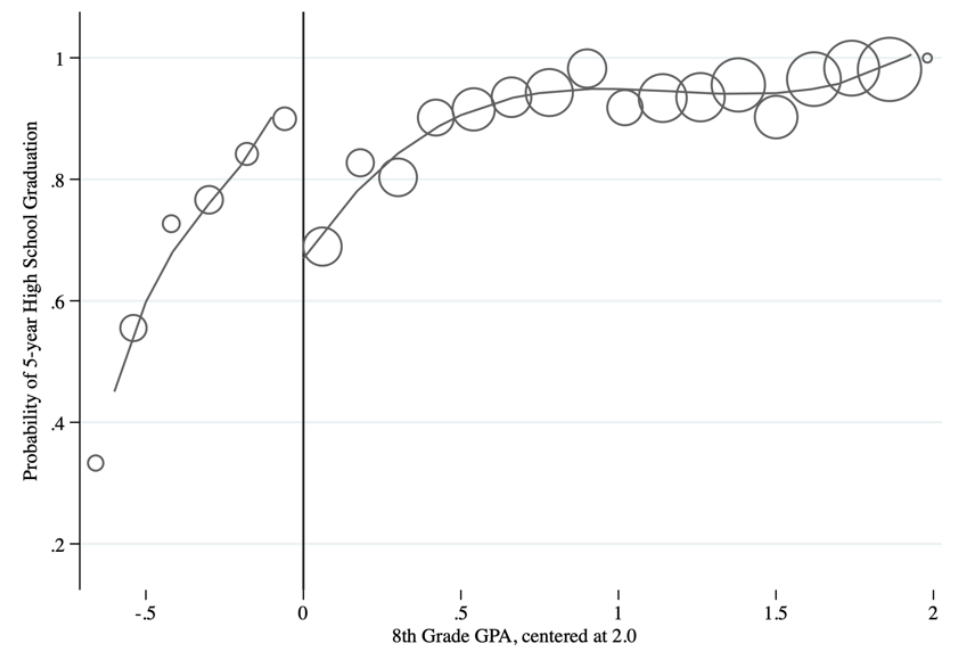

(c) Postsecondary enrollment year 5, full sample

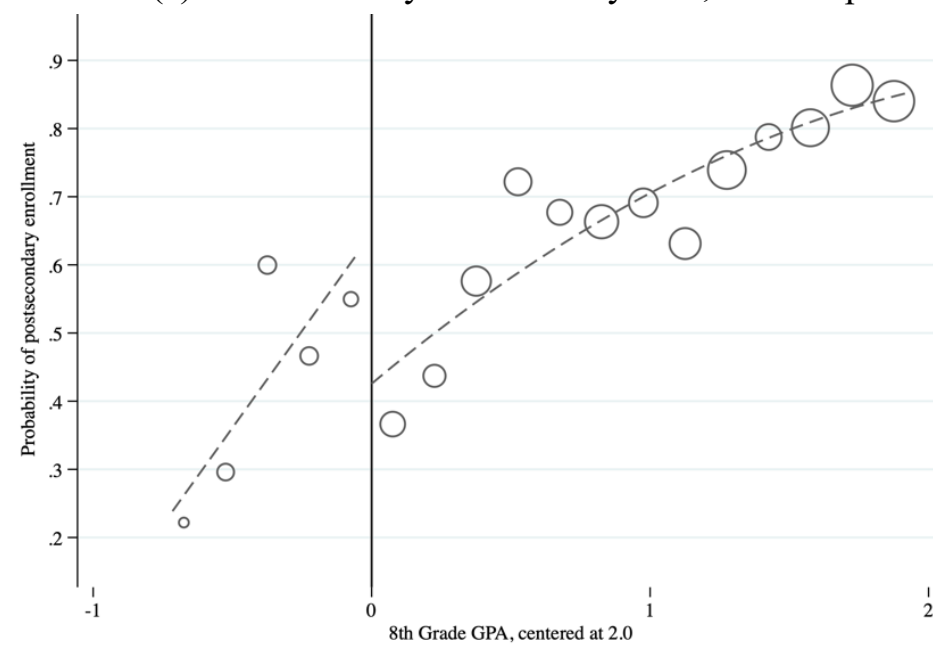

(e) Postsecondary enrollment year 6, full sample

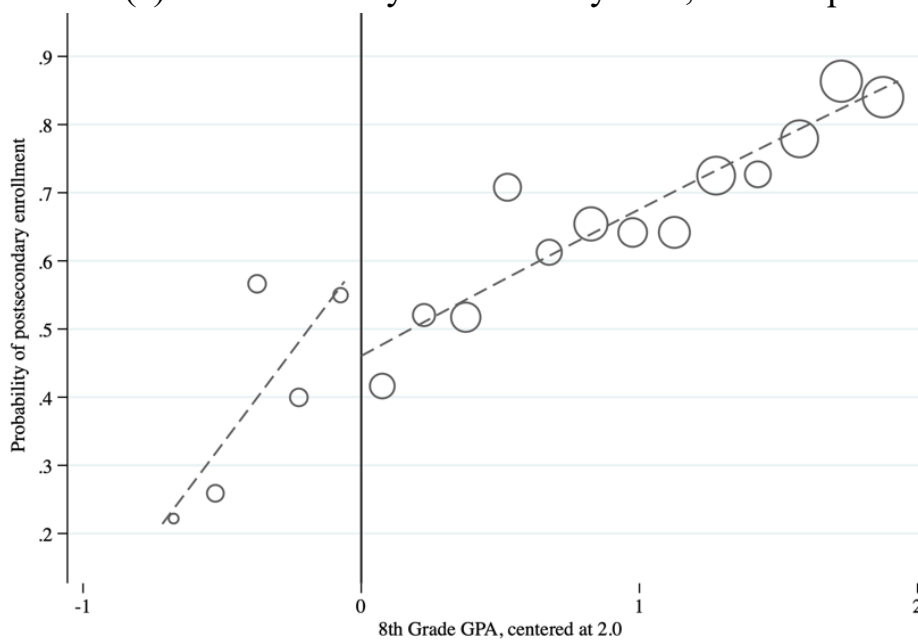

(b) High school graduation, Bandwidth +/- $1 \mathrm{SD}$

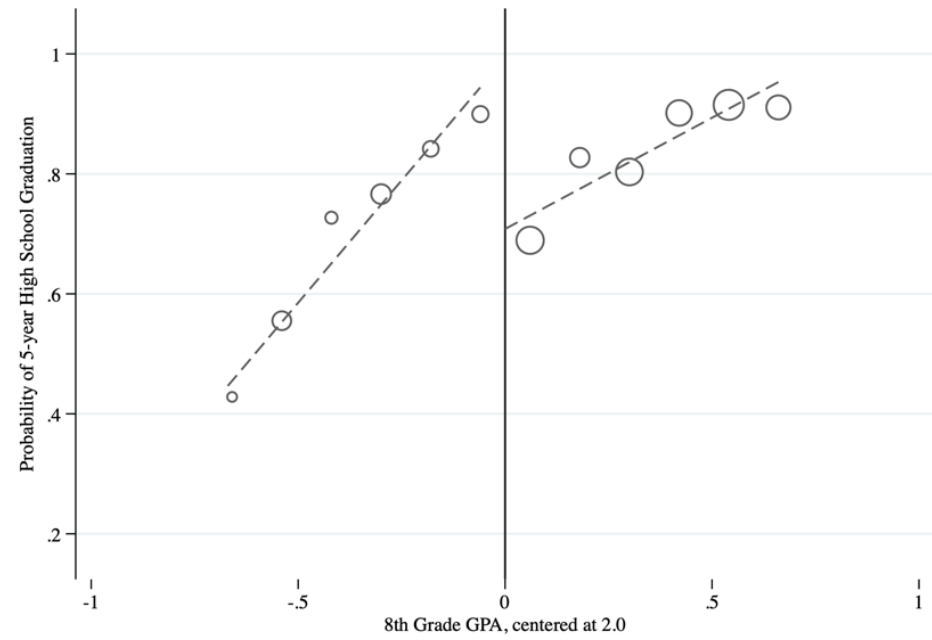

(d) Postsecondary enrollment year 5, Bandwidth +/- $1 \mathrm{SD}$

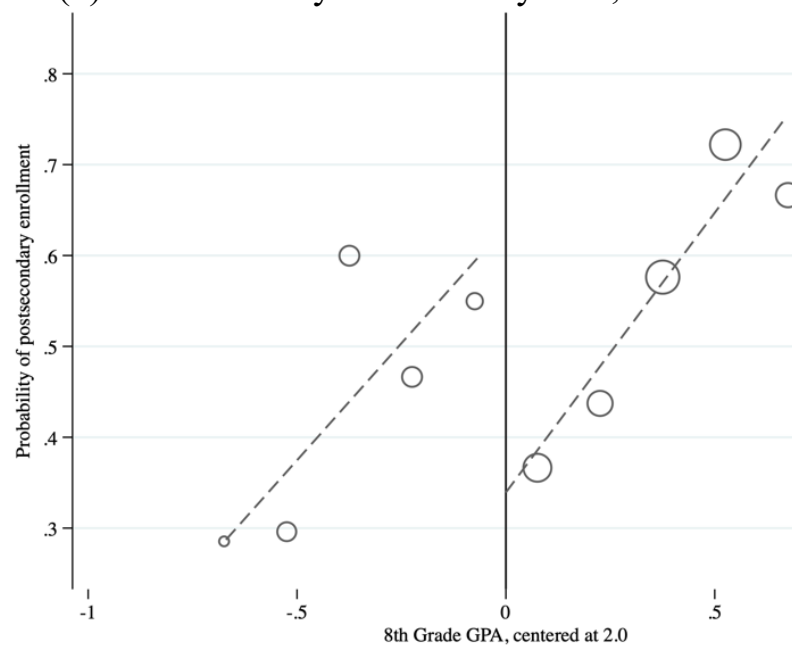

(f) Postsecondary enrollment year 6, Bandwidth +/- 1 SD

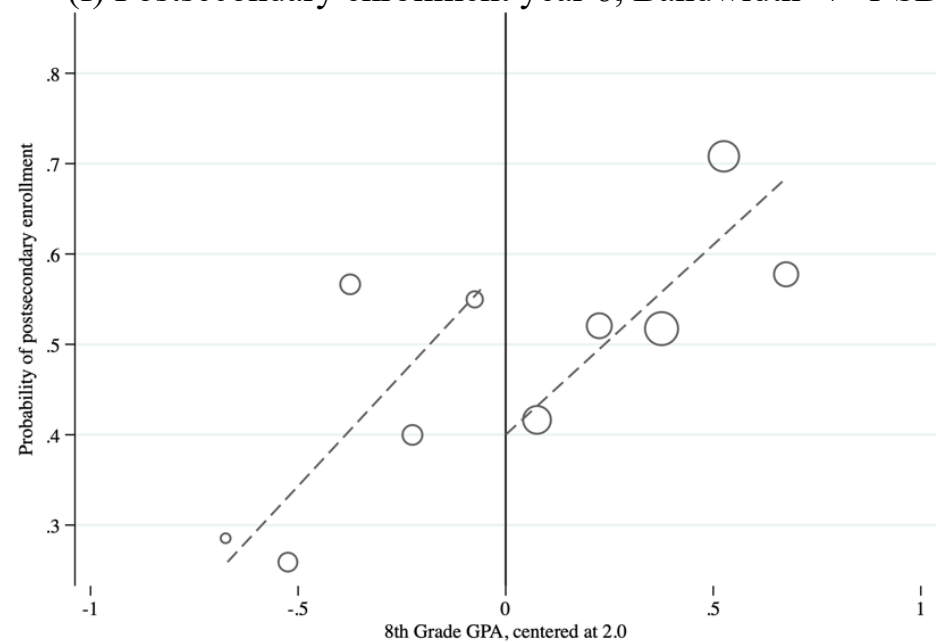

Figure 2. Educational Attainment

Notes. Graphs of the forcing variable (i.e., $8^{\text {th }}$ grade GPA) and measures of educational attainment (i.e., high school graduation, postsecondary enrollment). Graphs (a) and (b) utilize a bin width of 0.06. Graphs (c) through (f) use a bin width of 0.075 the forcing variable (i.e., $8^{\text {th }}$ grade GPA) and measures of high school persistence (i.e., district enrollment, attendance, and credits earned). All graphs contain the full sample and use a bin width of 0.075 . 
Table 1. Summary Statistics of Sample

\begin{tabular}{lccc}
\hline & Sample: & \multicolumn{3}{c}{ Full Sample } \\
\hline & mean & std. dev. & $\mathrm{N}$ \\
\cline { 2 - 4 } Enrolled in Ethnic Studies, year 1 & 0.127 & 0.334 & 1405 \\
I(Grade-8 GPA < 2.0) & 0.083 & 0.275 & 1405 \\
High school persistence & & & \\
Enrolled in SFUSD, year 2 & 0.974 & 0.158 & 1405 \\
Enrolled in SFUSD, year 3 & 0.949 & 0.221 & 1405 \\
Enrolled in SFUSD, year 4 & 0.928 & 0.258 & 1405 \\
Attendance, year 2 & 94.694 & 9.489 & 1369 \\
Attendance, year 3 & 93.054 & 10.667 & 1333 \\
Attendance, year 4 & 91.322 & 12.730 & 1304 \\
Credits earned, year 2 & 114.775 & 20.980 & 1369 \\
Credits earned, year 3 & 174.196 & 27.751 & 1333 \\
Credits earned, year 4 & 231.703 & 31.546 & 1304 \\
Educational Attainment & & & \\
High school graduate, year 5 & 0.900 & 0.301 & 1405 \\
High school graduate, imputed & 0.911 & 0.285 & 1405 \\
Enrolled in postsecondary, year 5 & 0.695 & 0.460 & 1405 \\
Enrolled in postsecondary, year 6 & 0.681 & 0.466 & 1405 \\
Baseline demographics & & & \\
Female & 0.417 & 0.493 & 1405 \\
Black & 0.063 & 0.242 & 1405 \\
Hispanic & 0.231 & 0.421 & 1405 \\
Asian & 0.601 & 0.490 & 1405 \\
Grade-8 special education & 0.123 & 0.329 & 1405 \\
Grade 8- English language learner & 0.184 & 0.388 & 1405 \\
Grade-8 ever suspended & 0.018 & 0.132 & 1405 \\
Grade-8 attendance & 96.684 & 3.141 & 1405 \\
\hline Not The full san & & & \\
& & &
\end{tabular}

Notes. The full sample includes $\mathrm{N}=1,405$ ninth graders from five cohorts who attended three district high schools beginning in the 2011-12, 2012-13 and 2014-15 school years. I(Grade-8 GPA $<2.0$ ) indicates a grade-8 GPA less than 2.0. High school graduation includes all students with a state-confirmed graduation status from any California public school (i.e, high school graduate, year 5). Our preferred imputed graduation status (i.e., high school graduate, imputed) imputes graduation for students who left the district and did not subsequently enroll in a California public school (i.e., enrolled in a private school, out-of-state public school or left to another country). We impute a positive graduation status for those who seamlessly enrolled in postsecondary or who at the time of leaving the school district earned enough credits to meet an internal district benchmarks for "on-track" to graduate. The high school graduation measure was the single confirmatory outcome preregistered (Bonilla, S., Dee, T. S., \& Penner, E. 2019) 
Table 2: Reduced-form RD effects on high school persistence, by year

\begin{tabular}{|c|c|c|c|c|c|c|}
\hline \multirow{3}{*}{ Dependent variable } & (1) & (2) & (3) & (4) & (5) & (6) \\
\hline & \multicolumn{3}{|c|}{ Full Sample } & \multicolumn{3}{|c|}{ Bandwidth $\mid$ Grade $8 \mathrm{GPA}_{\mathrm{i}} \mid \leq 0.67$} \\
\hline & estimate & $\underline{\mathrm{n}}$ & mean & estimate & $\underline{\mathrm{n}}$ & mean \\
\hline Enrolled in district, year 2 & $\begin{array}{l}-0.00987 \\
(0.0419)\end{array}$ & 1405 & 0.974 & $\begin{array}{l}0.0261 \\
(0.050)\end{array}$ & 424 & 0.960 \\
\hline Attendance, year 2 & $\begin{array}{l}5.741^{*} \\
(3.065)\end{array}$ & 1369 & 94.694 & $\begin{array}{l}9.672 * * * \\
(2.432)\end{array}$ & 407 & 90.034 \\
\hline Credits earned, year 2 & $\begin{array}{l}8.014^{*} \\
(4.794)\end{array}$ & 1369 & 114.775 & $\begin{array}{l}16.62 * * * \\
(5.739)\end{array}$ & 407 & 101.774 \\
\hline Enrolled in district, year 3 & $\begin{array}{l}0.00203 \\
(0.0516)\end{array}$ & 1405 & 0.949 & $\begin{array}{l}0.0511 \\
(0.060)\end{array}$ & 424 & 0.910 \\
\hline Attendance, year 3 & $\begin{array}{l}6.323 * * \\
(2.989)\end{array}$ & 1333 & 93.054 & $\begin{array}{l}9.677 * * * \\
(3.540)\end{array}$ & 386 & 87.284 \\
\hline Credits earned, year 3 & $\begin{array}{l}10.56 \\
(6.570)\end{array}$ & 1333 & 174.196 & $\begin{array}{l}24.66^{* * *} \\
(7.913)\end{array}$ & 386 & 156.056 \\
\hline Enrolled in district, year 4 & $\begin{array}{l}0.0374 \\
(0.0606)\end{array}$ & 1405 & 0.928 & $\begin{array}{l}0.0822 \\
(0.068)\end{array}$ & 424 & 0.868 \\
\hline Attendance, year 4 & $\begin{array}{l}7.158^{* * *} \\
(1.799)\end{array}$ & 1304 & 91.322 & $\begin{array}{l}11.56^{* * *} \\
(3.728)\end{array}$ & 368 & 84.713 \\
\hline Credits earned, year 4 & $\begin{array}{l}15.29 * * \\
(7.724)\end{array}$ & 1304 & 231.703 & $\begin{array}{l}31.46 * * * \\
(9.067)\end{array}$ & 368 & 212.706 \\
\hline
\end{tabular}

Notes: Each cell contains the result of a separate regression of the effect of $\mathrm{I}\left(\mathrm{Grade} 8 \mathrm{GPA}_{\mathrm{i}}<2.0\right)$ on high school persistence measures (i.e., district enrollment, attendance and credits earned) from administrative data. All models include linear splines and a full set of demographic controls (i.e., student sex and race/ethnicity indicators) and grade 8 (i.e., prior to treatment status) special education identification, English learner status, attendance and suspension history. Grade 8 GPA is centered at 2.0. Robust standard errors are reported in parentheses. ${ }^{*} p<.10 * * p<.05 * * *$ $n<n 1$ 
Table 3. Reduced-form RD Estimates of Educational Attainment

\begin{tabular}{|c|c|c|c|}
\hline & (1) & (2) & (3) \\
\hline Dependent variable: & \multicolumn{3}{|c|}{ High school graduate } \\
\hline $\mathrm{I}($ Grade 8 GPA $<2.0)$ & $\begin{array}{l}0.185^{* *} \\
(0.073)\end{array}$ & $\begin{array}{l}0.175^{* *} \\
(0.073)\end{array}$ & $\begin{array}{l}0.157^{* *} \\
(0.073)\end{array}$ \\
\hline $\mathrm{N}$ & 1405 & 1405 & 1405 \\
\hline $\mathrm{R}^{2}$ & 0.101 & 0.107 & 0.151 \\
\hline AIC & 323.5 & 321.8 & 259.5 \\
\hline Dependent variable: & \multicolumn{3}{|c|}{ Postsecondary enrollment, year 5} \\
\hline $\mathrm{I}($ Grade 8 GPA $<2.0)$ & $\begin{array}{l}0.163 \\
(0.101)\end{array}$ & $\begin{array}{l}0.162 \\
(0.0988)\end{array}$ & $\begin{array}{l}0.134 \\
(0.0920)\end{array}$ \\
\hline $\mathrm{N}$ & 1405 & 1405 & 1405 \\
\hline $\mathrm{R}^{2}$ & 0.0906 & 0.110 & 0.146 \\
\hline AIC & 1689.3 & 1667.0 & 1616.9 \\
\hline Dependent variable: & \multicolumn{3}{|c|}{ Postsecondary enrollment, year 6} \\
\hline $\mathrm{I}($ Grade 8 GPA $<2.0)$ & $\begin{array}{l}0.128 \\
(0.100)\end{array}$ & $\begin{array}{l}0.127 \\
(0.098)\end{array}$ & $\begin{array}{l}0.0976 \\
(0.092)\end{array}$ \\
\hline $\mathrm{N}$ & 1405 & 1405 & 1405 \\
\hline $\mathrm{R}^{2}$ & 0.0957 & 0.115 & 0.155 \\
\hline AIC & 1716.5 & 1694.4 & 1637.9 \\
\hline Demographic controls & - & Yes & Yes \\
\hline Full controls & - & - & Yes \\
\hline
\end{tabular}

Notes: Each cell contains the results of a separate regression of the effect of I(Grade $\left.8 \mathrm{GPA}_{\mathrm{i}}<2.0\right)$ on graduation outcomes confirmed by the California Department of Education (CDE) from any public school in the state. High school graduation is our preferred measure that includes imputed outcomes for district and state leavers (i.e., enrolled in private school, public school out-of-state or left country) who enrolled seamlessly in postsecondary or were on-track to graduate based on internal district benchmarks for credits earned. All models contain linear splines. Demographic controls include student sex and race/ethnicity. The full controls include grade 8 (i.e., prior to treatment status) special education identification, English learner status, attendance and suspension history. Grade 8 GPA is centered at 2.0. Robust standard errors are reported in parentheses. ${ }^{*} \mathrm{p}<$ $.10 * * \mathrm{p}<.05 * * * \mathrm{p}<.01$ 
Table 4. Reduced-form RD estimates of educational attainment with bandwidth restrictions

\begin{tabular}{|c|c|c|c|c|}
\hline \multirow{2}{*}{ Dependent variable: } & $(1)$ & $(2)$ & $(3)$ & (4) \\
\hline & $\begin{array}{c}\text { High School } \\
\text { Graduate, year } 5\end{array}$ & $\begin{array}{c}\text { Postsecondary } \\
\text { enrollment, year } 5\end{array}$ & $\begin{array}{c}\text { Postsecondary } \\
\text { enrollment, year } 6\end{array}$ & \\
\hline Sample & estimate & estimate & estimate & $\underline{\mathrm{n}}$ \\
\hline Full Sample, linear splines & $\begin{array}{l}0.157^{* *} \\
(0.073)\end{array}$ & $\begin{array}{l}0.134 \\
(0.0920)\end{array}$ & $\begin{array}{l}0.149 \\
(0.091)\end{array}$ & 1405 \\
\hline Full sample, linear and quadratic & $\begin{array}{l}0.140 \\
(0.122)\end{array}$ & $\begin{array}{l}0.0618 \\
(0.253)\end{array}$ & $\begin{array}{l}0.202 \\
(0.253)\end{array}$ & 1405 \\
\hline $\mid$ Grade $8 \mathrm{GPA}_{\mathrm{i}} \mid \leq 1.00$ & $\begin{array}{l}0.226 * * * \\
(0.079)\end{array}$ & $\begin{array}{l}0.192 * \\
(0.098)\end{array}$ & $\begin{array}{l}0.187^{*} \\
(0.098)\end{array}$ & 634 \\
\hline $\mid$ Grade $8 \mathrm{GPA}_{\mathrm{i}} \mid \leq 0.67$ & $\begin{array}{l}0.251 * * * \\
(0.087)\end{array}$ & $\begin{array}{l}0.260^{* *} \\
(0.105)\end{array}$ & $\begin{array}{l}0.249 * * \\
(0.104)\end{array}$ & 424 \\
\hline $\mid$ Grade $8 \mathrm{GPA}_{\mathrm{i}} \mid \leq 0.50$ & $\begin{array}{l}0.298^{* * *} \\
(0.096)\end{array}$ & $\begin{array}{l}0.268^{* *} \\
(0.115)\end{array}$ & $\begin{array}{l}0.261^{* *} \\
(0.115)\end{array}$ & 341 \\
\hline $\mid$ Grade $8 \mathrm{GPA}_{\mathrm{i}} \mid \leq 0.33$ & $\begin{array}{l}0.232 * * \\
(0.110)\end{array}$ & $\begin{array}{l}0.107 \\
(0.150)\end{array}$ & $\begin{array}{l}0.117 \\
(0.153)\end{array}$ & 208 \\
\hline $\mid$ Grade $8 \mathrm{GPA}_{\mathrm{i}} \mid \leq 0.25$ & $\begin{array}{l}0.237^{*} \\
(0.140)\end{array}$ & $\begin{array}{l}0.259 \\
(0.188)\end{array}$ & $\begin{array}{l}0.316^{*} \\
(0.185)\end{array}$ & 157 \\
\hline Kernel Weights & $\begin{array}{l}0.256^{* * * *} \\
(0.088)\end{array}$ & $\begin{array}{l}0.224 * * \\
(0.113)\end{array}$ & $\begin{array}{l}0.235^{* *} \\
(0.111)\end{array}$ & 424 \\
\hline CCT Optimal & $\begin{array}{l}0.162 \\
(0.161)\end{array}$ & $\begin{array}{l}0.185 \\
(0.232)\end{array}$ & $\begin{array}{l}0.370 \\
(0.225)\end{array}$ & $126,105,106$ \\
\hline IK Optimal & $\begin{array}{l}0.256^{* * *} \\
(0.092)\end{array}$ & $\begin{array}{l}0.200 \\
(0.122)\end{array}$ & $\begin{array}{l}0.218^{*} \\
(0.121)\end{array}$ & $357,443,438$ \\
\hline $\begin{array}{l}\text { Demographic controls } \\
\text { Full controls }\end{array}$ & $\begin{array}{l}\text { Yes } \\
\text { Yes }\end{array}$ & $\begin{array}{l}\text { Yes } \\
\text { Yes }\end{array}$ & $\begin{array}{l}\text { Yes } \\
\text { Yes }\end{array}$ & \\
\hline
\end{tabular}

Notes: Each cell contains the results of a separate regression of the effect of I(Grade $\left.8 \mathrm{GPA}_{\mathrm{i}}<2.0\right)$ on educational attainment (i.e., high school graduation and postsecondary enrollment). High school graduation is our preferred measure that includes imputed outcomes for district and state leavers (i.e., enrolled in private school, public school outof-state or left country) who enrolled seamlessly in postsecondary or were on-track to graduate based on internal district benchmarks for credits earned. CCT= Calonico, Cattaneo \& Titunik; IK =Imbens \& Kalyanaraman. Kernel, CCT and IK estimates utilize triangular kernels. All other estimates utilize uniform weights. Demographic controls include student sex and race/ethnicity. The full controls include grade 8 (i.e., prior to treatment status) special education identification, English learner status, attendance and suspension history. Grade 8 GPA is centered at 2.0. Robust standard errors are reported in parentheses. $* \mathrm{p}<.10 * * \mathrm{p}<.05 * * * \mathrm{p}<.01$ 


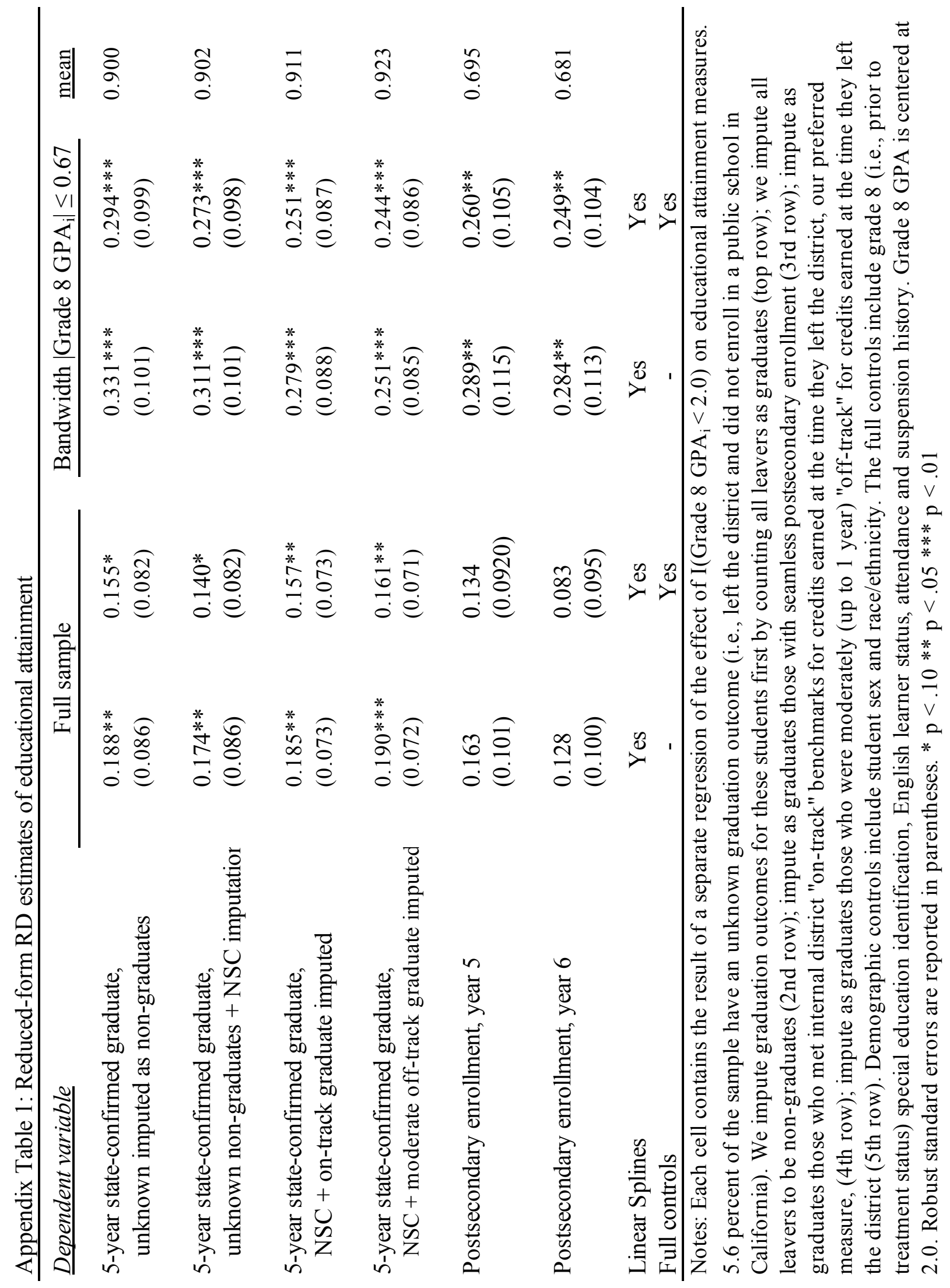


Appendix Table 2: Auxiliary RD estimates of baseline covariate balance

\begin{tabular}{|c|c|c|c|c|}
\hline Dependent variable & Full & & $\mathrm{n}$ & mean \\
\hline Available Grade 8 ELA Score & $\begin{array}{l}0.00140 \\
(0.063)\end{array}$ & $\begin{array}{l}0.0813 \\
(0.093)\end{array}$ & 1405 & 0.908 \\
\hline Available Grade 8 History Score & $\begin{array}{l}0.00907 \\
(0.007)\end{array}$ & $\begin{array}{l}0.00968 \\
(0.012)\end{array}$ & 1405 & 0.987 \\
\hline Available Grade 8 Math Score & $\begin{array}{l}-0.0277 \\
(0.058)\end{array}$ & $\begin{array}{l}0.0195 \\
(0.088)\end{array}$ & 1405 & 0.932 \\
\hline Grade 8 ELA Score, standardized & $\begin{array}{l}-0.0318 \\
(0.287)\end{array}$ & $\begin{array}{l}-0.104 \\
(0.224)\end{array}$ & 1276 & -0.065 \\
\hline Grade 8 History Score, standardized & $\begin{array}{l}0.230 \\
(0.241)\end{array}$ & $\begin{array}{l}0.149 \\
(0.216)\end{array}$ & 1387 & -0.086 \\
\hline Grade 8 Math Score, standardized & $\begin{array}{l}0.201 \\
(0.247)\end{array}$ & $\begin{array}{l}0.0159 \\
(0.239)\end{array}$ & 1310 & 0.0658 \\
\hline Female & $\begin{array}{l}0.0142 \\
(0.090)\end{array}$ & $\begin{array}{l}-0.156 \\
(0.148)\end{array}$ & 1405 & 0.417 \\
\hline Black & $\begin{array}{l}0.0899 \\
(0.071)\end{array}$ & $\begin{array}{l}-0.0333 \\
(0.113)\end{array}$ & 1405 & 0.063 \\
\hline Hispanic & $\begin{array}{l}-0.0401 \\
(0.098)\end{array}$ & $\begin{array}{l}-0.0984 \\
(0.176)\end{array}$ & 1405 & 0.868 \\
\hline Asian & $\begin{array}{l}0.0643 \\
(0.098)\end{array}$ & $\begin{array}{l}0.205 \\
(0.175)\end{array}$ & 1405 & 0.601 \\
\hline Grade 8, Special Education & $\begin{array}{l}-0.00924 \\
(0.078)\end{array}$ & $\begin{array}{l}-0.0506 \\
(0.120)\end{array}$ & 1405 & 0.123 \\
\hline Grade 8, English Learner & $\begin{array}{l}-0.0415 \\
(0.092)\end{array}$ & $\begin{array}{l}0.0217 \\
(0.176)\end{array}$ & 1405 & 0.184 \\
\hline Grade 8, Ever suspended & $\begin{array}{l}0.00897 \\
(0.036)\end{array}$ & $\begin{array}{l}-0.0910^{*} \\
(0.044)\end{array}$ & 1405 & 0.018 \\
\hline Grade 8 , Attendance & $\begin{array}{l}1.198 \\
(0.658)\end{array}$ & $\begin{array}{l}2.073 \\
(1.112)\end{array}$ & 1405 & 96.684 \\
\hline $\begin{array}{l}\text { Linear Splines } \\
\text { Quadratic Splines }\end{array}$ & $\begin{array}{c}\text { Yes } \\
-\end{array}$ & $\begin{array}{l}\text { Yes } \\
\text { Yes }\end{array}$ & & \\
\hline
\end{tabular}

Notes: Each cell contains the result of a separate regression of $\mathrm{I}\left(\mathrm{Grade} 8 \mathrm{GPA}_{\mathrm{i}}<2.0\right)$ on baseline covariates. Test scores are standardized using the full sample of school district grade 8 students who participated in the exam. Grade $8 \mathrm{GPA}$ is centered at 2.0. Robust standard errors are reported in parentheses.

$* \mathrm{p}<.05 * * \mathrm{p}<.01 * * * \mathrm{p}<.001$ 


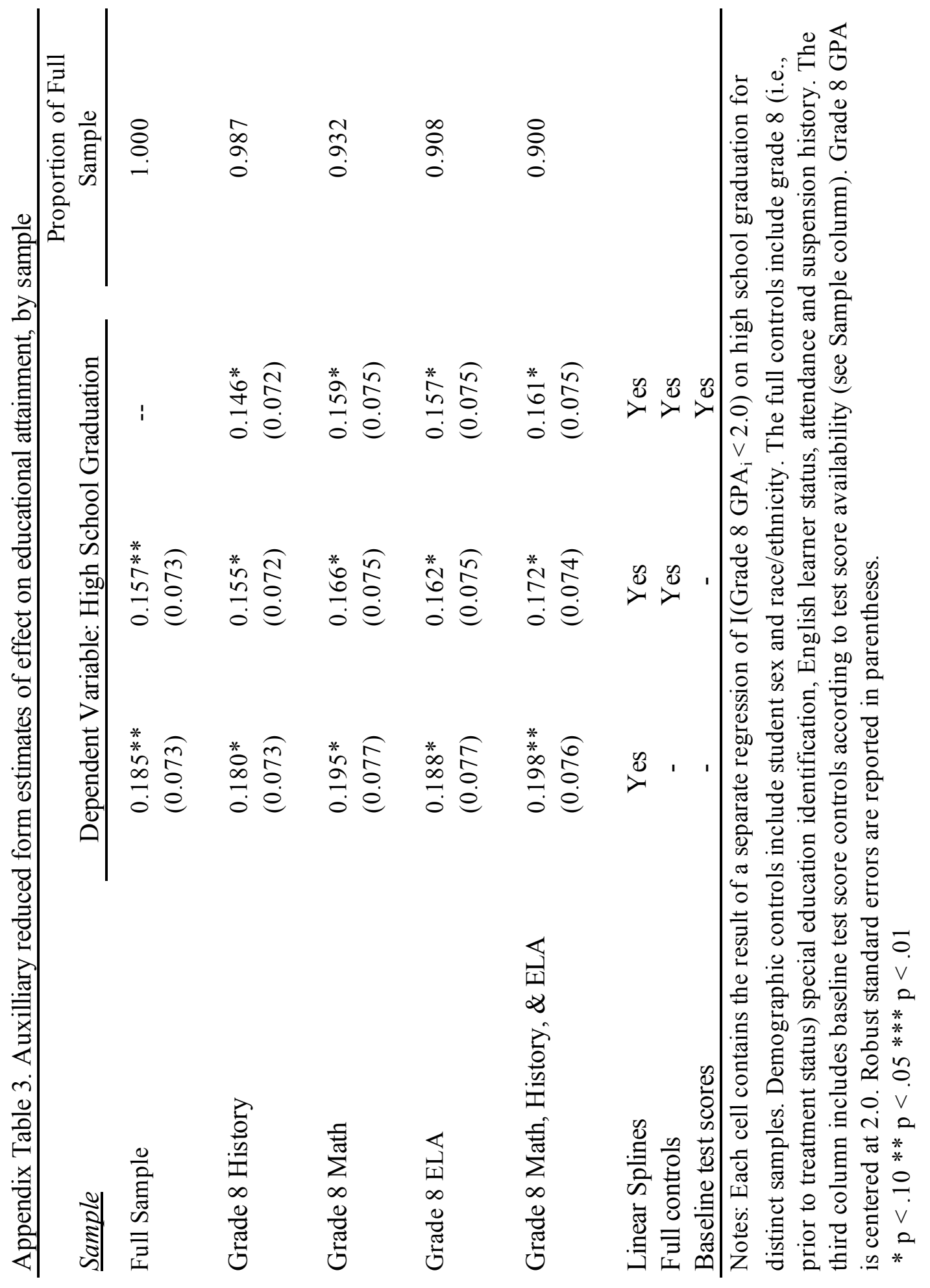


Appendix Table 4. Reduced-form placebo RD effects on high school persistence, by year

\begin{tabular}{|c|c|c|c|c|c|c|}
\hline \multirow{3}{*}{ Dependent variable } & (1) & $(2)$ & (3) & (4) & $(5)$ & (6) \\
\hline & \multicolumn{3}{|c|}{ Full Sample } & \multicolumn{3}{|c|}{ Bandwidth $\mid$ Grade $8 \mathrm{GPA}_{\mathrm{i}} \mid \leq 0.67$} \\
\hline & estimate & $\underline{\mathrm{n}}$ & mean & estimate & $\underline{\mathrm{n}}$ & mean \\
\hline Enrolled in district, year 2 & $\begin{array}{l}0.0496 \\
(0.0322)\end{array}$ & 2861 & 0.973 & $\begin{array}{l}0.0554 \\
(0.040)\end{array}$ & 655 & 0.955 \\
\hline Attendance, year 2 & $\begin{array}{l}-3.395 \\
(2.935)\end{array}$ & 2783 & 94.402 & $\begin{array}{l}-2.406 \\
(3.346)\end{array}$ & 615 & 88.107 \\
\hline Credits earned, year 2 & $\begin{array}{l}-5.924 \\
(5.438)\end{array}$ & 2783 & 120.785 & $\begin{array}{l}-2.003 \\
(6.506)\end{array}$ & 615 & 83.566 \\
\hline Enrolled in district, year 3 & $\begin{array}{l}-0.00161 \\
(0.0561)\end{array}$ & 2861 & 0.949 & $\begin{array}{l}-0.00242 \\
(0.064)\end{array}$ & 655 & 0.911 \\
\hline Attendance, year 3 & $\begin{array}{l}-5.661 \\
(3.627)\end{array}$ & 2715 & 93.111 & $\begin{array}{l}-5.038 \\
(4.380)\end{array}$ & 587 & 85.582 \\
\hline Credits earned, year 3 & $\begin{array}{l}-5.716 \\
(7.731)\end{array}$ & 2715 & 182.445 & $\begin{array}{l}-0.237 \\
(9.405)\end{array}$ & 587 & 159.797 \\
\hline Enrolled in district, year 4 & $\begin{array}{l}0.0239 \\
(0.0627)\end{array}$ & 2861 & 0.932 & $\begin{array}{l}0.0126 \\
(0.074)\end{array}$ & 655 & 0.873 \\
\hline Attendance, year 4 & $\begin{array}{l}0.540 \\
(3.468)\end{array}$ & 2667 & 90.955 & $\begin{array}{l}3.283 \\
(4.218)\end{array}$ & 562 & 83.566 \\
\hline Credits earned, year 4 & $\begin{array}{l}-5.367 \\
(8.502)\end{array}$ & 2667 & 243.768 & $\begin{array}{l}1.801 \\
(10.815)\end{array}$ & 562 & 222.350 \\
\hline
\end{tabular}

Notes: Each cell contains the result of a separate regression of the placebo (i.e., early warning indicator (EWI) label only) effect of I(Grade $\left.8 \mathrm{GPA}_{\mathrm{i}}<2.0\right)$ on high school persistence measures (i.e., district enrollment, attendance and credits earned) from administrative data. The placebo sample includes students at district schools that did not implement the Ethnic Studies curriculum. All models include linear splines and a full set of demographic controls (i.e., student sex and race/ethnicity indicators) and grade 8 (i.e., prior to treatment status) special education identification, English learner status, attendance and suspension history. Grade 8 GPA is centered at 2.0. Robust standard errors are reported in parentheses. ${ }^{*} \mathrm{p}<.10 * * \mathrm{p}<.05 * * * \mathrm{p}<.01$ 


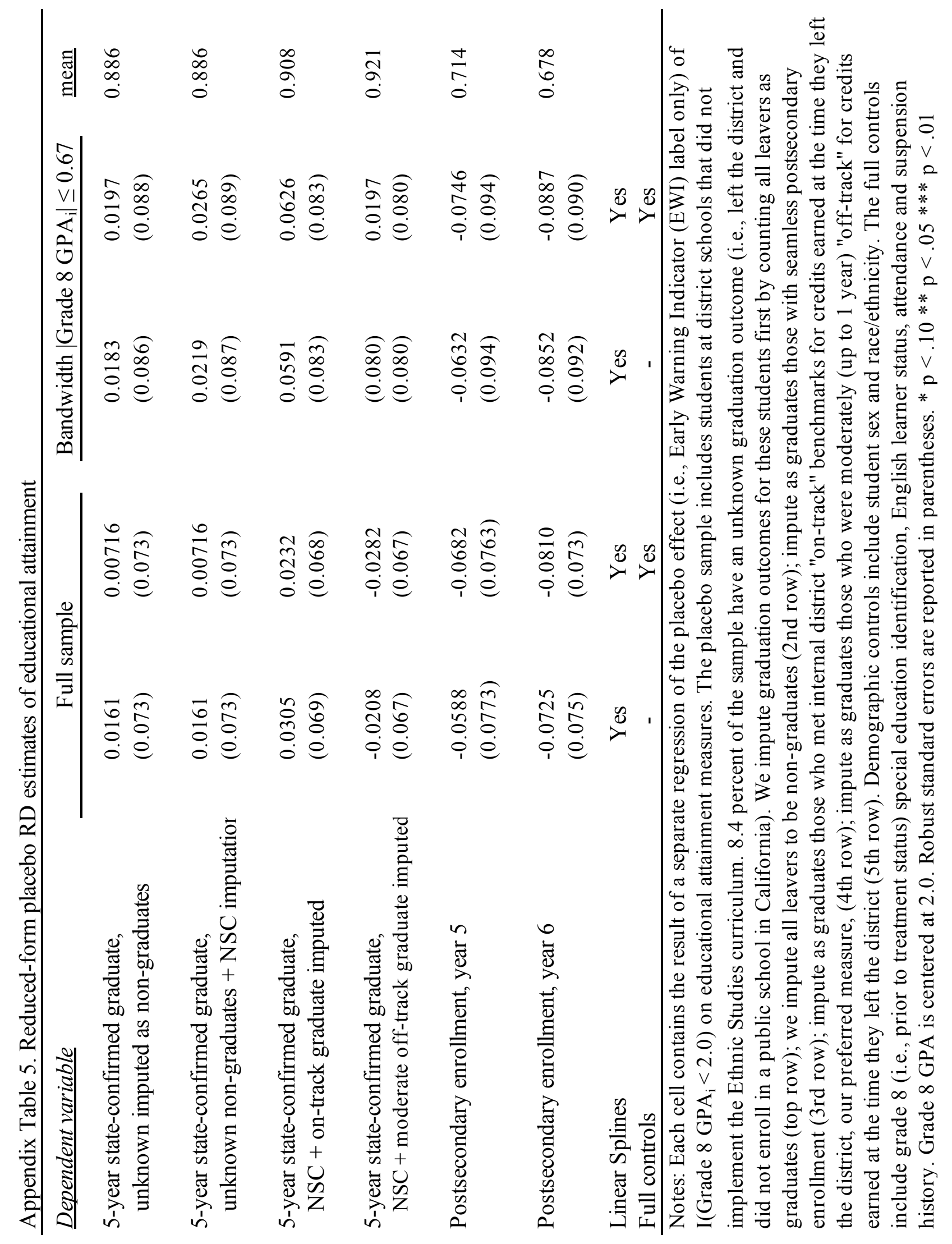


Appendix Table 6. Reduced-form Difference in Discontinuity effects on outcomes

\begin{tabular}{|c|c|c|c|c|}
\hline \multirow{3}{*}{ Dependent variable } & (1) & (2) & (3) & (4) \\
\hline & \multicolumn{2}{|c|}{ RD Estimates } & \multicolumn{2}{|c|}{$\begin{array}{c}\text { Difference in Discontinuity } \\
\text { Estimates }\end{array}$} \\
\hline & estimate & $\underline{\mathrm{n}}$ & estimate & $\underline{\mathrm{n}}$ \\
\hline High school graduate & $\begin{array}{l}0.157^{* *} \\
(0.073)\end{array}$ & 1405 & $\begin{array}{l}0.151^{*} \\
(0.073)\end{array}$ & 4266 \\
\hline Enrolled in district, year 2 & $\begin{array}{l}-0.00987 \\
(0.0419)\end{array}$ & 1405 & $\begin{array}{l}-0.0535 \\
(0.0351)\end{array}$ & 4266 \\
\hline Attendance, year 2 & $\begin{array}{l}5.741 * \\
(3.065)\end{array}$ & 1369 & $\begin{array}{l}11.07 * * * \\
(3.130)\end{array}$ & 4152 \\
\hline Credits earned, year 2 & $\begin{array}{l}8.014 * \\
(4.794)\end{array}$ & 1369 & $\begin{array}{l}13.83^{* *} \\
(5.948)\end{array}$ & 4152 \\
\hline Enrolled in district, year 3 & $\begin{array}{l}0.00203 \\
(0.0516)\end{array}$ & 1405 & $\begin{array}{l}-0.00381 \\
(0.0746)\end{array}$ & 4266 \\
\hline Attendance, year 3 & $\begin{array}{l}6.323^{* *} \\
(2.989)\end{array}$ & 1333 & $\begin{array}{l}11.37 * * * \\
(3.781)\end{array}$ & 4048 \\
\hline Credits earned, year 3 & $\begin{array}{l}10.56 \\
(6.570)\end{array}$ & 1333 & $\begin{array}{l}16.04 * \\
(9.224)\end{array}$ & 4048 \\
\hline Enrolled in district, year 4 & $\begin{array}{l}0.0374 \\
(0.0606)\end{array}$ & 1405 & $\begin{array}{l}0.0262 \\
(0.0856)\end{array}$ & 4266 \\
\hline Attendance, year 4 & $\begin{array}{l}7.158^{* * *} \\
(1.799)\end{array}$ & 1304 & $\begin{array}{l}5.626 \\
(4.083)\end{array}$ & 3971 \\
\hline Credits earned, year 4 & $\begin{array}{l}15.29 * * \\
(7.724)\end{array}$ & 1304 & $\begin{array}{l}20.16^{*} \\
(10.07)\end{array}$ & 3971 \\
\hline
\end{tabular}

Notes: Each cell contains the result of a separate regression of the effect of I(Grade $\left.8 \mathrm{GPA}_{\mathrm{i}}<2.0\right)$ interacted with an indicator for attending an ES pilot school (i.e., ITT=1) on high school graduation and persistence measures (i.e., district enrollment, attendance and credits earned) from administrative data. These models estimate the reduced form effect of ES eligibility conditioned on a placebo jump for those students at EWI-only intervention schools (i.e., difference in discontinuity). As such, all models include a linear spline of the forcing variable (i.e., Grade 8 GPA), an indicator for Grade 8 GPA $<2.0$, and those RD specification variables interacted with an indicator for attending an ES pilot school. Additionally, all models include school-year fixed effects (i.e., cohort fixed effects) and a full set of demographic controls (i.e., student sex and race/ethnicity indicators) and grade 8 (i.e., prior to treatment status) special education identification, English learner status, attendance and suspension history. Grade 8 GPA is centered at 2.0. Robust standard errors are reported in parentheses. $* \mathrm{p}<.10$ $*_{*} n<n 5 * * *_{n}<n 1$ 


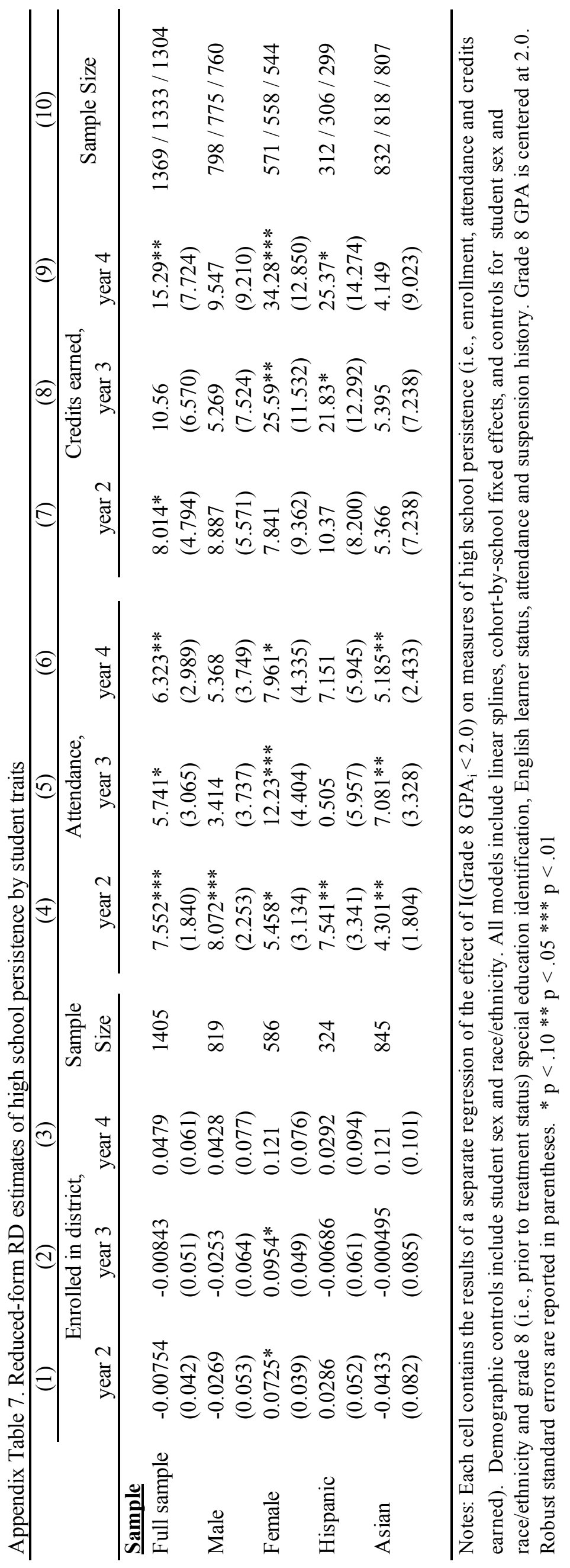




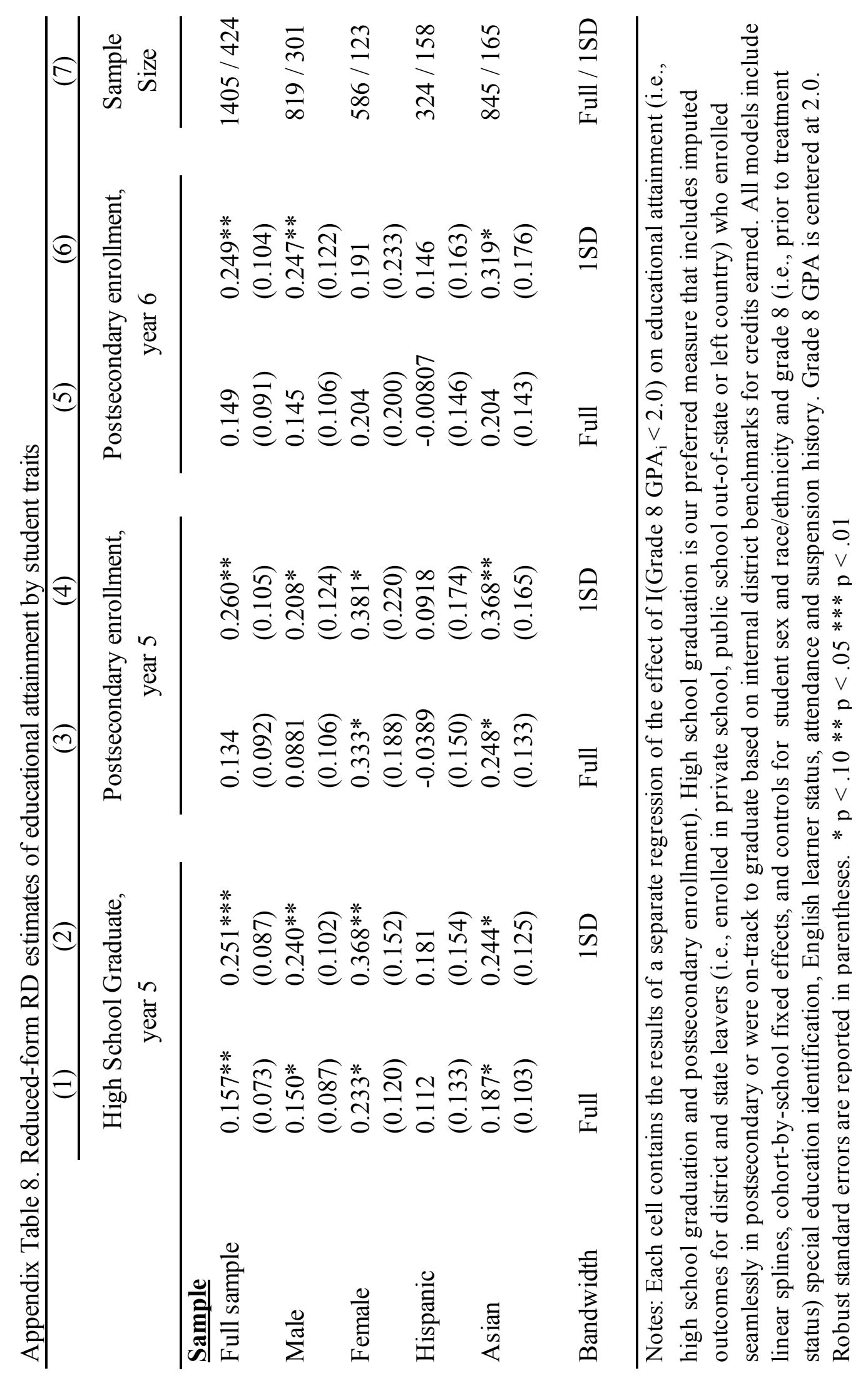




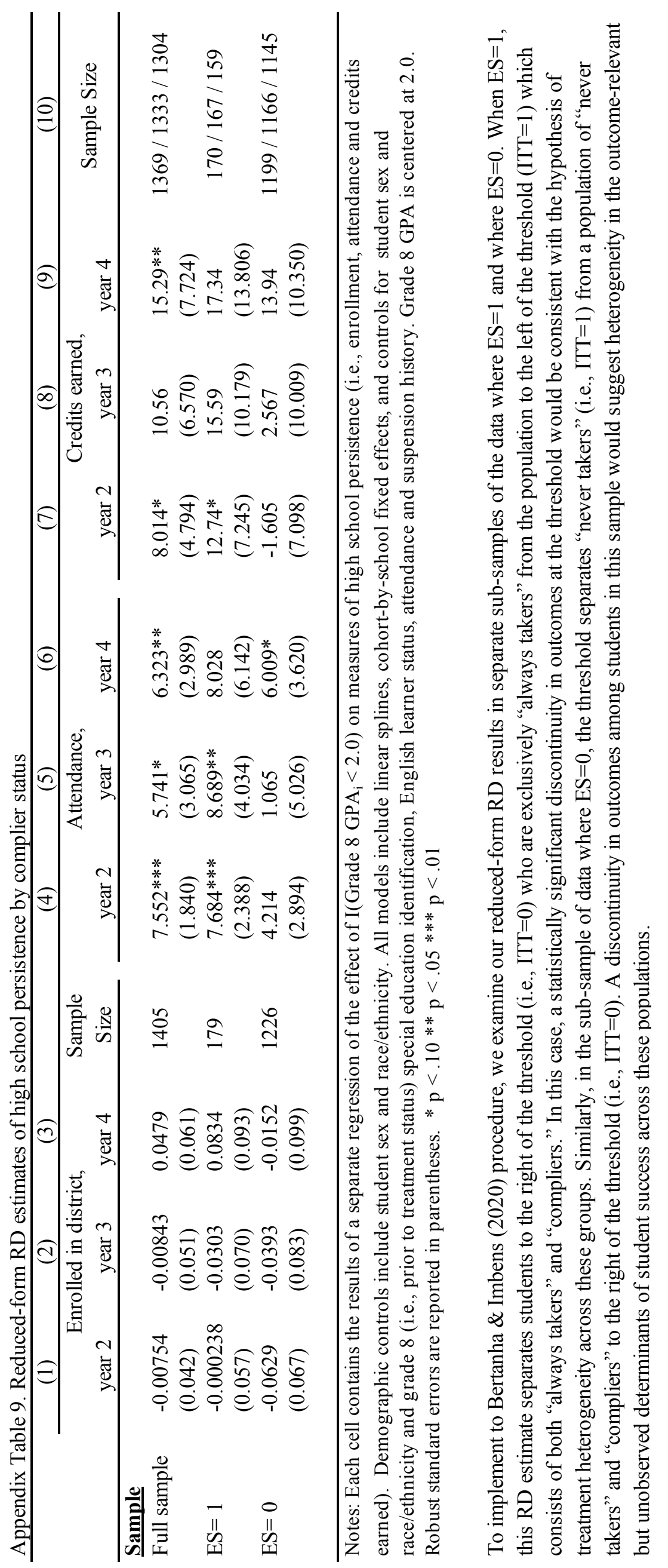




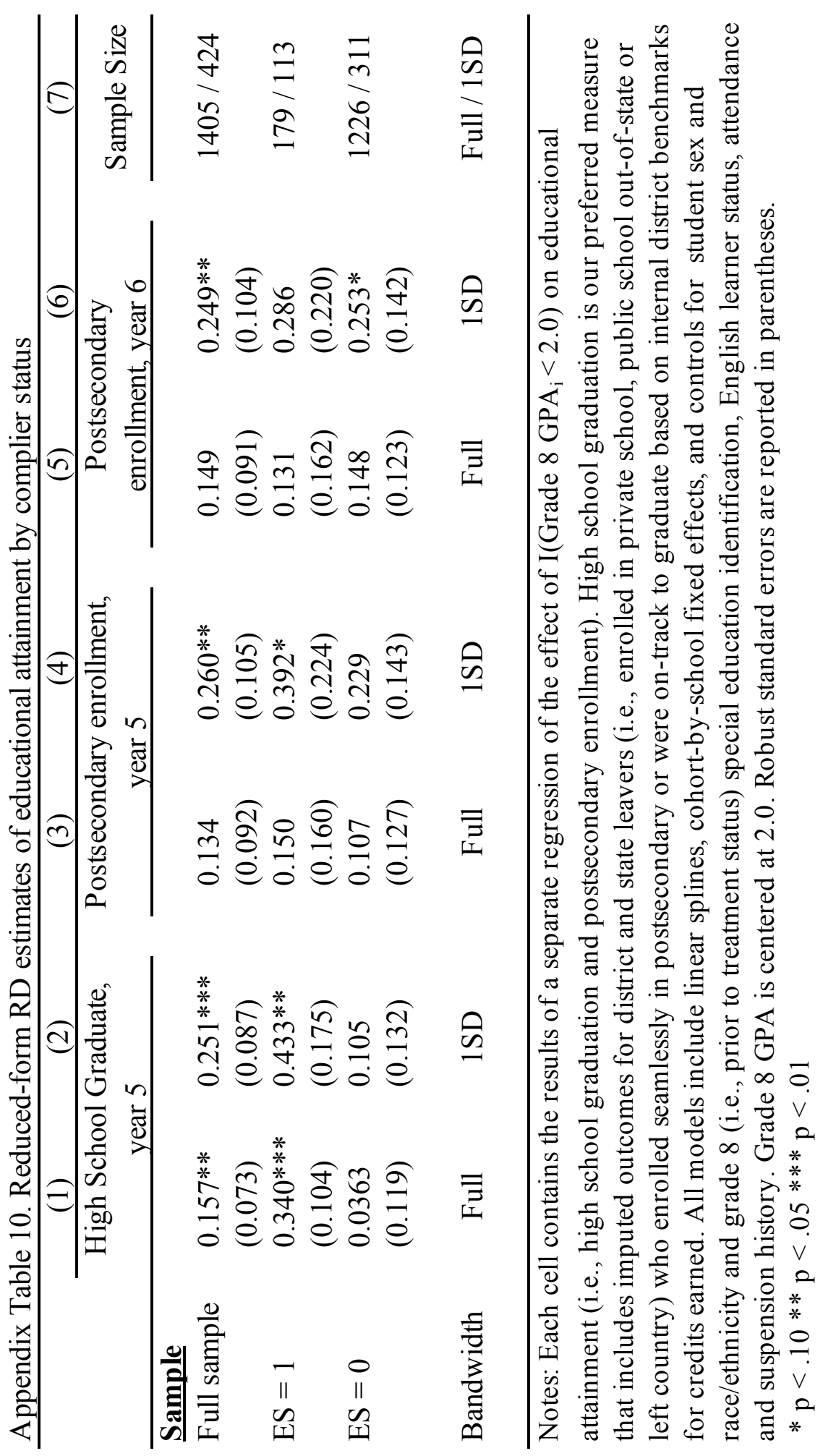

